\title{
Pleiotropic Properties of Amphiphilic Dihydropyridines, Dihydropyridones, and Aminovinylcarbonyl Compounds
}

\author{
Martins Rucins $\mathbb{D},{ }^{1}$ Rufus Smits $\left(\mathbb{D},{ }^{1}\right.$ Anda Sipola $\left(\mathbb{D},{ }^{1}\right.$ Brigita Vigante $\mathbb{D}^{1}$, \\ Ilona Domracheva $\mathbb{D}^{1},{ }^{1}$ Baiba Turovska ${ }^{\mathbb{D}},{ }^{1}$ Ruslan Muhamadejev ${ }^{D},{ }^{1}$ Karlis Pajuste $\mathbb{D}^{\mathbb{D}},{ }^{1}$ \\ Mara Plotniece $\mathbb{D}^{2}{ }^{2}$ Arkadij Sobolev $\mathbb{D}^{1},{ }^{1}$ Gunars Duburs $\mathbb{D}^{1},{ }^{1}$ and Aiva Plotniece $\mathbb{D}^{1}$ \\ ${ }^{1}$ Latvian Institute of Organic Synthesis, Aizkraukles 21, Riga LV-1006, Latvia \\ ${ }^{2}$ Department of Pharmaceutical Chemistry, Faculty of Pharmacy, Riga Stradiņš University, Dzirciema 16, Riga LV-1007, Latvia \\ Correspondence should be addressed to Gunars Duburs; gduburs@osi.lv and Aiva Plotniece; aiva@osi.lv
}

Received 23 July 2020; Revised 9 October 2020; Accepted 10 November 2020; Published 31 December 2020

Academic Editor: Sasanka Chakrabarti

Copyright (C) 2020 Martins Rucins et al. This is an open access article distributed under the Creative Commons Attribution License, which permits unrestricted use, distribution, and reproduction in any medium, provided the original work is properly cited.

\begin{abstract}
Three groups of synthetic lipids are chosen for studies: (1) 1,4-dihydropyridines (1,4-DHPs) containing two cationic moieties and their analogues; (2) 3,4-dihydro-2(1H)-pyridones containing a cationic moiety; and (3) acyclic, open-chain analogues, i.e., 2amino-3-alkoxycarbonylalkylammonium derivatives. 1,4-DHPs possessing dodecyl alkyl chains in the ester groups in positions 3 and 5 and cationic nitrogen-containing groups in positions 2 and 6 have high cytotoxicity in cancer cells HT-1080 (human lung fibrosarcoma) and $\mathrm{MH}-22 \mathrm{~A}$ (mouse hepatoma), but low cytotoxicity in the noncancerous NIH3T3 cells (mouse embryonic fibroblast). On the contrary, similar compounds having short (methyl, ethyl, or propoxyethyl) chains in the ester groups in positions 3 and 5 lack cytotoxicity in the cancer cells HT-1080 and MH-22A even at high doses. Inclusion of fluorine atoms in the alkyl chains in positions 3 and 5 of the DHP cycle decreases the cytotoxicity of the mentioned compounds. Structurally related dihydropyridones with a polar head group are substantially more toxic to normal and cancerous cells than the DHP analogues. Open-chain analogues of DHP lipids comprise the same conjugated aminovinylcarbonyl moiety and possess anticancer activity, but they also have high basal cytotoxicity. Electrochemical oxidation data demonstrate that oxidation potentials of selected compounds are in the range of $1.6-1.7 \mathrm{~V}$ for cationic 1,4DHP, 2.0-2.4 V for cationic 3,4-dihydropyridones, and 1.2-1.5 V for 2-amino-3-alkoxycarbonylalkylammonium derivatives. Furthermore, the tested cationic 1,4-DHP amphiphiles possess antiradical activity. Molecular topological polar surface area values for the tested compounds were defined in accordance with the main fragments of compound structures. The determined $\log P$ values were highest for dodecyl ester groups in positions 3 and 5 of the 1,4-DHP and lowest for short alkyl chain-containing amphiphiles.
\end{abstract}

\section{Introduction}

For a long time, liposomes have been considered to have a role in the encapsulation of toxic drugs (mainly anticancer drugs) into liposomal drug delivery systems which are supposed to be inert, having no pharmacological or chemotherapeutical activity per se [1]. The properties of liposomes are mainly dependent on the characteristics of their constituent lipids.

Lipids and liposomal agents as liposome-forming building blocks depending on their physicochemical properties can influence the immune system. For the development of new liposomal systems, it is important to perform analysis on the liposome-forming lipid properties with an emphasis on toxicity to healthy tissues and immune responses [2]. Synthetic cationic amphiphilic bilayers can act as gene, vaccine, or drug carriers; at the same time, they can interact with negatively charged prokaryotic or eukaryotic cells, causing cell adhesion and loss of cell viability. Lipids and liposomes deserve to be investigated as potential drugs [3]. Cytotoxicity of cationic liposomes is a significant property to be checked [4].

Liposomes may induce oxidative damage to normal tissues [5]. Reactive oxygen species (ROS) and lipid peroxidation 
products not only are cytotoxic but may also perform and modulate signal transduction in cells [6]. It was demonstrated that the levels of ROS and the activity of scavenging/antioxidant enzymes in drug-resistant cancer cells are typically increased compared to nonresistant cancer and normal cells. Thereby, multidrug-resistant (MDR) cancer cells may be more susceptible to alterations in ROS levels. Numerous studies suggest that compounds modulating cellular ROS levels can enhance MDR cancer cell death and sensitize MDR cancer cells to certain chemotherapeutic drugs [7]. It was concluded that unspecific elimination of ROS by use of low molecular mass antioxidants was not successful for disease initiation and progression. However, controlling specific ROSmediated signaling pathways by selective targeting offers a perspective for more refined redox medicine in the future [8]. Additional antioxidant activity (antiradical activity) could be beneficial as it would protect cells and organisms in case of oxidative stress or, in general, be involved in the process of redox regulation and master switch systems [9]. In this way, 1,4-dihydropyridines, being a group of synthetic antioxidants, could be used for the modulation of cellular redox signaling. Lipids reveal cancer cell-selective cytotoxicities-they are less cytotoxic in noncancerous healthy cells [10]. Evaluation of the cytotoxicity of nanoparticles and their components is crucial for the accurate interpretation of pharmacological activities [11]. Nonviral synthetic lipid vectors may interact with biomolecules through functional moieties (biosignature), resulting in biological impacts: intrinsic genomic and nongenomic effects [12].

Our research group has developed liposome-forming cationic 1,4-dihydropyridine (1,4-DHP) amphiphiles capable of transfecting pDNA into different cell lines in vitro. To assess the influence of different molecular architectures on gene delivery properties, numerous 1,4-DHP amphiphiles were studied [13-15]. Besides, some of these amphiphilic compounds revealed anticancer activity in HT-1080 and MH$22 \mathrm{~A}$ cells and antiradical activities (27-40\% in DPPH tests) $[13,16]$. The remarkable increase of $\mathrm{N}-\mathrm{H}$ acidity (up to $\mathrm{pKa} \sim 7-8)$ in the DHP cycle is the basis for its buffering activity in these types of gene transfection agents [17].

Recently, it was demonstrated that 4-(N-alkylpyridinium)-1,4-dihydropyridines possess toxicity in Grampositive and Gram-negative bacteria species and eukaryotic microorganisms [18]. The abovementioned 4-(N-alkylpyridinium)-1,4-dihydropyridines also possess calcium channelblocking and antioxidant activities [19].

In this work, we chose amphiphilic dihydropyridine derivatives as synthetic lipids and their structural analogues as objects to study pleiotropic activities. The cytotoxic properties of 3 types of amphiphilic compounds in 3 cell lines, namely, normal NIH3T3 (mouse embryonic fibroblast), cancerous HT-1080 (human lung fibrosarcoma), and MH-22A (mouse hepatoma), were evaluated. The studied compounds could be divided into 3 groups according to their structural fragments: (a) 1,4-dihydropyridines containing two cationic moieties as a conjugated cyclic bis( $\beta$-carbonylvinyl)amino system and some structurally related compounds; (b) 3,4dihydro-2(1H)-pyridones containing a cationic moiety as an isomeric 3,4-dihydropyridine structure with an additional intracyclic carbonyl group-a N- $\beta$-carbonylvinylamido system; and (c) 2-amino-3-alkoxycarbonylalkylammonium derivatives as acyclic, open-chain $\beta$-aminovinylcarbonyl systems. Lipophilicity of the selected compounds was characterized using $\log P$ and molecular topological polar surface area calculations. Evaluation of electrochemical oxidation potentials of the selected compounds was also performed.

\section{Materials and Methods}

2.1. Chemistry. More detailed descriptions of synthetic procedures and characterization of the original unpublished intermediates and compounds are described in the Supplementary data.

2.1.1. Synthesis of Cationic 1,4-Dihydropyridines 1-26. Briefly, the elaborated synthesis of the cationic 1,4-DHP 1-7, 9-25 involved three sequential steps. The first step was the synthesis of the corresponding 2,6-dimethyl 1,4-DHP derivative in a two-component Hantzsch-type cyclization using 1.0 eq of the corresponding aldehyde, $1.2 \mathrm{eq}$ of an ammonia source, and $2.0 \mathrm{eq}$ of the corresponding acetoacetate for symmetrically substituted 1,4-DHP derivatives or 1 eq of the corresponding acetoacetate and $1.0 \mathrm{eq}$ of the corresponding 3-aminobut-2enoate for unsymmetrically substituted ones. The second step involved the bromination of the methyl groups of the 2,6dimethyl-1,4-DHP derivative with N-bromosuccinimide, and the third step was the nucleophilic substitution of bromine of the 2,6-dibromomethylene-1,4-DHP by N-heterocycles or amines yielding the target compounds. The first step for the synthesis of the parent 1,4-dihydropyridine in the case of compound 26 involved the reaction between $1.0 \mathrm{eq}$ of the corresponding aldehyde, $2.4 \mathrm{eq}$ of ammonium acetate, and $4.0 \mathrm{eq}$ of the corresponding acetoacetate. More detailed synthetic procedures and characterization of the original compounds are described in the Supplementary data.

2.1.2. Synthesis of Compound 8 [20]. Briefly, the condensation of ethyl 4-chloroacetoacetate with glyoxylic acid monohydrate in the presence of piperidine/acetate provided (E,Z)-2-(2-chloroacetyl)-but-2-enedioic acid 1-ethyl ester, which was used in the next reaction with ethyl 3amino-4-chlorobut-2-enoate. The obtained 3,5-diethyl 2,6-bis(chloromethyl)-1,4-dihydropyridine-3,4,5-tricarboxylate was esterified with methanol to afford the parent 2,6dichloromethylene-1,4-DHP. The target compound 8 was obtained via nucleophilic substitution of chlorine by pyridine in the presence of potassium iodide.

2.1.3. Synthesis of Cationic Pyridine 27 [14]. Briefly, the corresponding 2,6-dibromomethylene-1,4-DHP was oxidized by $\mathrm{HNO}_{2}$ followed by nucleophilic substitution of bromine with pyridine to give the target compound 27.

2.1.4. Synthesis of Cationic 3,4-Dihydro-2(1H)-pyridones 2838. Briefly, 3,4-dihydro-2(1H)-pyridone synthesis employed a four-component reaction using Meldrum's acid by a heterocyclization with the corresponding $\beta$-ketoester and the corresponding aldehyde. The obtained 3,4-dihydro-2(1H)pyridones were treated with bromine giving the respective 
6-methylbromides, which in subsequent reaction with pyridine or amine provided the target compounds 28-38.

2.1.5. Synthesis of 2-Amino-3-alkoxycarbonylalkylammonium Halides 39-48. Briefly, the first step included the transesterification of the commercially available ethyl 4-chloroacetoacetate with a corresponding carbinol without solvent by azeotropic removal of ethanol. The further reaction of the corresponding 4-chloro-3-oxobutanoates with ammonium acetate led to enaminoesters, which were used for quaternization by tertiary amines or heterocycles giving the target compounds 39-48. Potassium iodide or sodium bromide additives were used for obtaining the corresponding iodides or bromides.

2.2. Experiments for Evaluation of Electrochemical Oxidation Potentials. Cyclic voltammetry experiments were carried out on a PARSTAT 2273 electrochemical system. A stationary glassy carbon disk electrode $(d=0.5 \mathrm{~mm})$ served as the working electrode, while the counterelectrode was a $\mathrm{Pt}$ wire. The oxidation potentials were measured relative to a $\mathrm{Ag} / \mathrm{Ag}^{+}$reference electrode. Acetonitrile was dried over $\mathrm{P}_{2} \mathrm{O}_{5}$ and distilled; the distillate was stored over $\mathrm{CaH}_{2}$ and redistilled just before use. Recrystallized tetrabutylammonium tetrafluoroborate $\left(\mathrm{TBABF}_{4}\right)$ was used as a supporting electrolyte at $0.1 \mathrm{M}$ concentration.

2.3. Determination of LogP and Molecular Topological Polar Surface Area. $\log P$ and Topological Polar Surface Area (TPSA) values were calculated with the Chem3D Ultra 19 program (PerkinElmer Informatics). For $\log P$ calculations, the Molecular Networks module was used on singlemolecule compounds (salts were taken as cations).

2.4. Cytotoxicity. Cytotoxicity of the compounds was determined on HT-1080 (human lung fibrosarcoma) and $\mathrm{MH}-$ 22A (mouse hepatoma) cell lines and on the normal NIH3T3 (mouse embryonic fibroblast) cell line. $\mathrm{IC}_{50}$ is the compound concentration $(\mu \mathrm{g} / \mathrm{ml})$ at which $50 \%$ of the cells die. CV is a triarylmethane dye that can bind to ribose-type molecules such as DNA in nuclei. CV staining can be used to quantify the total DNA of the remaining population and thus is used to determine the number of live cells based on the concentration of the dye which remains after staining. MTT is a standard colorimetric assay used to measure cellular proliferation. Yellow MTT (3-(4,5-dimethylthiazol2-yl)-2,5-diphenyltetrazolium bromide) is reduced to purple formazan in the mitochondria of living cells.

Reduction takes place only when mitochondrial reductase enzymes are active, and therefore, conversion is directly related to the number of viable cells which can be quantified by the absorbance of the solution (between $\lambda=500$ and $600 \mathrm{~nm}$ ) using a spectrophotometer.

2.5. Cell Culture and Measurement of Cell Viability. Tumor cell lines HT-1080 (human connective tissue fibrosarcoma, ATCC $^{\circledR}$ CCL-121 ${ }^{\mathrm{TM}}$ ) and MH-22A (mouse hepatocarcinoma, ECACC, cat. Nr. 96121721) were used.

HT-1080 and MH-22A cells were seeded in 96-well plates in Dulbecco's modified Eagle's (DMEM) medium containing $10 \%$ fetal bovine serum and $4 \mathrm{mM}$ L-glutamine, without antibiotics, and cultivated for $72 \mathrm{~h}$ by exposure to different concentrations of compounds. Cell viability was measured using 3-(4,5-dimethylthiazol-2-yl)-2,5-diphenyltetrazolinium bromide (MTT). In brief, after incubating with compounds, the culture medium was removed and fresh medium with $0.2 \mathrm{mg} / \mathrm{ml}$ MTT was added in each well of the plate. After incubation $\left(3 \mathrm{~h}, 37^{\circ} \mathrm{C}, 5 \% \mathrm{CO}_{2}\right)$, the medium with MTT was removed, and $200 \mu \mathrm{l}$ DMSO was added at once to each sample. The samples were tested at $540 \mathrm{~nm}$ on a Tecan Infinite M1000 multiplate reader. The $\mathrm{IC}_{50}$ was calculated using the program GraphPad Prism ${ }^{\circledR}$ 3.0.

For the CV assay, cells were stained with $0.05 \%$ crystal violet (Sigma-Aldrich) in 30\% methanol for 20 minutes at room temperature. After incubation, the staining solution was removed. The cells were washed 4 times with water. For dye solubilization, $200 \mu \mathrm{l}$ of a solubilizing solution ( $0.1 \mathrm{M}$ citrate buffer, $\mathrm{pH} 4.2$ in $50 \%$ ethanol; $1: 1 \mathrm{v} / \mathrm{v})$ was added. The absorbance of the solution was measured using a Tecan Infinite M1000 multiplate spectrophotometer at a wavelength of $570 \mathrm{~nm}$ [21].

2.6. Basal Cytotoxicity Test. The Neutral Red Uptake (NRU) assay was performed according to the standard protocol of Stokes et al. [22] modified by a NICEATM-ECVAM validation study [23]. The NRU cytotoxicity assay procedure is based on the ability of viable cells to incorporate and bind neutral red, a supravital dye.

Balb/c NIH 3T3 (mouse Swiss albino embryo fibroblast, ATCC ${ }^{\circledR}$ CRL-1658 ${ }^{\mathrm{TM}}$ ) cells (9000 cells/well) were placed into 96-well plates for $24 \mathrm{~h}$ in Dulbecco's modified Eagle's medium (DMEM) containing 5\% fetal bovine serum. Then, the cells were exposed to the test compound over a range of seven concentrations $(1000,316,100,31,10,3$, and $1 \mu \mathrm{g} / \mathrm{ml})$ for $24 \mathrm{~h}$. Untreated cells were used as a control. After $24 \mathrm{~h}$, the medium was removed from all plates. Then, $150 \mu$ l of neutral red solution was added $(0.05 \mathrm{mg} / \mathrm{ml} \mathrm{NR}$ in DMEM $24 \mathrm{~h}$ preincubated at $37^{\circ} \mathrm{C}$ and then filtered before use through a $0.22 \mu \mathrm{m}$ syringe filter). Plates were incubated for $3 \mathrm{~h}$, and then, the cells were washed three times with PBS. The dye within viable cells was released by extraction with a mixture of acetic acid, ethanol, and water $(1: 50: 49)$. The absorbance of neutral red was measured using a spectrophotometer multiplate reader (Tecan Infinite M1000) at $540 \mathrm{~nm}$. The optical density (OD) was calculated using the following formula: $\mathrm{OD}$ (treated cells) $\times 100 / \mathrm{OD}$ (control cells). The $\mathrm{IC}_{50}$ values were calculated using the GraphPad Prism ${ }^{\circledR} 3.0$ program.

2.7. Estimation of $L D_{50}$ from $I C_{50}$ Values. Data from the in vitro tests were used for estimating the starting dose for acute oral systemic toxicity tests in the rodent. The in vivo starting dose is an estimated $\mathrm{LD}_{50}$ value calculated by inserting the in vitro $\mathrm{IC}_{50}$ value into a regression formula: $\log \mathrm{LD}_{50}(\mathrm{mM} / \mathrm{kg})=0.439 \log \mathrm{IC}_{50}(\mathrm{mM})+0.621$ [23-25]. The value is recalculated to $\mathrm{mg} / \mathrm{kg}$, and compounds are evaluated in accordance with 4 toxicity categories [26]: category $1-\mathrm{LD}_{50} \leq 5 \mathrm{mg} / \mathrm{kg}$ (highly toxic); category $2-5<\mathrm{LD}_{50} \leq 50 \mathrm{mg} / \mathrm{kg}$ (moderately toxic); category $3-50<\mathrm{LD}_{50} \leq 300 \mathrm{mg} / \mathrm{kg}$ (slightly toxic); and 
category $4-300<\mathrm{LD}_{50} \leq 2000 \mathrm{mg} / \mathrm{kg}$ (practically nontoxic). Using an alternative in vitro method allows the comparison between possibly toxic new compounds and selecting compounds for further study vastly reducing the number of animal experiments.

\section{Results and Discussion}

3.1. Structures of Compounds. The studied compounds could be divided into 3 groups considering structure fragments:

(1) 1st group: twenty-five representatives of two cationic moieties containing 1,4-dihydropyridines (compounds 1-25 in Table 1) and, additionally, four cationic moieties containing 1,4-dihydropyridine (compound 26 in Table 1) and one as an oxidized form-two cationic moieties containing pyridine (compound 27 in Table 1)

(2) 2nd group: eleven representatives of 3,4-dihydro$2(1 H)$-pyridones containing a cationic moiety as an isomeric 3,4-dihydropyridine structure with an additional intracyclic carbonyl group, i.e., the N- $\beta$-carbonylvinylamido system (compounds $\mathbf{2 8 - 3 8}$ in Table 2)

(3) 3rd group: ten representatives of cationic 2-amino-3alkoxycarbonylalkylammonium derivatives as acyclic, open-chain analogues of cyclic 1,4-DHPs (compounds 39-48 in Table 3)

These three groups were selected after analysis of their structure-activity relationships as synthetic lipid-like amphiphilic compounds. Previously, the 3rd group representatives-(2-amino-3-alkoxycarbonylalkyl)trialkylammonium halides-were synthesized, and their ribonucleic acid (RNS) transfection activity was demonstrated [27]. This group covers synthetic lipid-like compounds on the basis of a $\beta$ aminovinylcarbonyl (AVC) moiety: a conjugated pentade system connected with a lipophilic carbon atom chain and a cationic part (alkylammonium or pyridinium type). These compounds are proposed as an open-chain system compared to the cationic 1,4-DHP or pyridone heterocyclic systems. Structurally, the 2 nd group molecules - the cationic pyridone derivatives-are heterocycles which comprise a cyclic AVC system and an additional intracyclic carbonyl group and an extracyclic cation. Previously, the 1st group representatives-1,4-DHP derivatives containing pyridinium moieties-were presented as promising tools for delivery of DNA into target cells $[13,14,20,28]$. It is noteworthy that, due to cross-conjugation of two AVC systems of the 1,4DHP cycle, its N-H group is influenced by two electronwithdrawing vinylcarbonyls.

3.2. Synthesis of the Amphiphiles. Synthesis of the amphiphiles was performed according to Schemes 1-4.

Previously, 3,5-bis(dodecyloxycarbonyl)-1,4-DHPs containing cationic moieties were elaborated as synthetic lipidlike compounds having promising gene delivery properties for DNA transfection; the basic structure-activity relationships have been verified for the cationic 1,4-DHP derivatives as gene delivery systems, and it has been shown that the molecular structure affected their self-assembling properties, pDNA-binding ability, and properties of the formed 1,4DHP amphiphile-pDNA complexes $[13,15,28]$. The synthetic procedure for the amphiphilic compounds 1-7, 9-22, and $\mathbf{2 6}$ is displayed in Scheme 1via a multistep sequence. The first step was a Hantzsch synthesis of the parent compound 3,5-bis(alkoxycarbonyl)-2,6-dimethyl-4-phenyl-1,4dihydropyridine. The second step was bromination of the 2,6-methyl groups with N-bromosuccinimide (NBS) [34] resulting in the second parent compound 2,6-di(bromomethyl)-3,5-bis(alkoxycarbonyl)-4-phenyl-1,4-dihydropyridine. The final step was nucleophilic substitution of bromine in the 2,6-di(bromomethyl)-1,4-DHP by N-heterocycles or amines, which is facile and generally takes place in good yields.

Additionally, for studies of targeted changes in the structure of corresponding dicationic compound 10, which was found to be more active for DNA delivery among the tested 1,4-DHP amphiphiles $[13,15,28], 1,1^{\prime}, 1^{\prime \prime}, 1^{\prime \prime \prime}-((1,4-$ phenylenebis(3,5-bis((dodecyloxy)carbonyl)-1,4-dihydropyridine4,2,6-triyl))tetrakis(methylene))tetrakis(pyridin-1-ium) tetrabromide (26) was synthesized as a double or a "dimeric" molecule of compound 10 and $1,1^{\prime}$ - ((3,5-bis(dodecyloxycarbonyl)-4-phenylpyridine-2,6-diyl)bis(methylene))-bis(pyridin-1-ium)dibromide (27) was prepared in accordance with what was reported in [14] as the oxidized form of compound 10. For evaluation of the anion influence on cytotoxicity, $1,1^{\prime}$ -((3,5-bis((dodecyloxy)carbonyl)-4-phenyl-1,4-dihydropyridine-2,6-diyl)bis(methylene))bis(pyridin-1-ium) ditetrafluoroborate (11) was synthesized from compound $\mathbf{1 0}$ after treating with $\mathrm{NH}_{4} \mathrm{BF}_{4}$.

The unsymmetrical 1,4-DHP amphiphile 23 was designed for analysis of the influence of mixed perfluorinated and alkyl ester moiety substituents on the properties of amphiphiles. The 1,4-DHP 23 molecule contains only one of the two esters as a perfluorinated ester moiety while the other is an alkyl ester-the same as previous compounds. The synthetic procedure (Scheme 2) includes a reaction between an enamine and benzylidene in diglyme with inclusion of n-butylpyridinium chloride as a phase transfer catalyst (PTC) [35] to affording the parent dodecyl 5,5,6,6,7,7,8,8,9,9,10,10,11,11,12,12,12heptadecafluorododecyl 1,4-dihydro-2,6-dimethyl-4-phenylpyridine-3,5-dicarboxylate in $43 \%$ yield. Without the PTC, the yield was only $25 \%$. Subsequent bromination with NBS formed the corresponding 2,6-dibromomethylene DHP which was used without further purification in nucleophilic substitution with pyridine yielding the unsymmetrical 1,4-DHP 23.

The 3,4-dihydro-2(1H)-pyridones (DHPDO) possess various pharmacological properties as $\alpha 1 \mathrm{a}$ adrenergic receptor antagonists [36], Rho-kinase inhibitors [37], $\mathrm{P}_{2} \mathrm{X}_{7}$ receptor antagonists [38], or G-protein-coupled kinase receptor antagonists [39]. Synthesis of 3,4-dihydro-2(1H)-pyridone amphiphiles 28-38 was performed according to Scheme 3 . In this case, Meldrum's acid was used as the second dicarbonyl component in a Hantzsch-like reaction with heterocyclization, with a corresponding $\beta$-ketoester and a corresponding aldehyde in the presence of ammonium acetate in refluxing glacial 

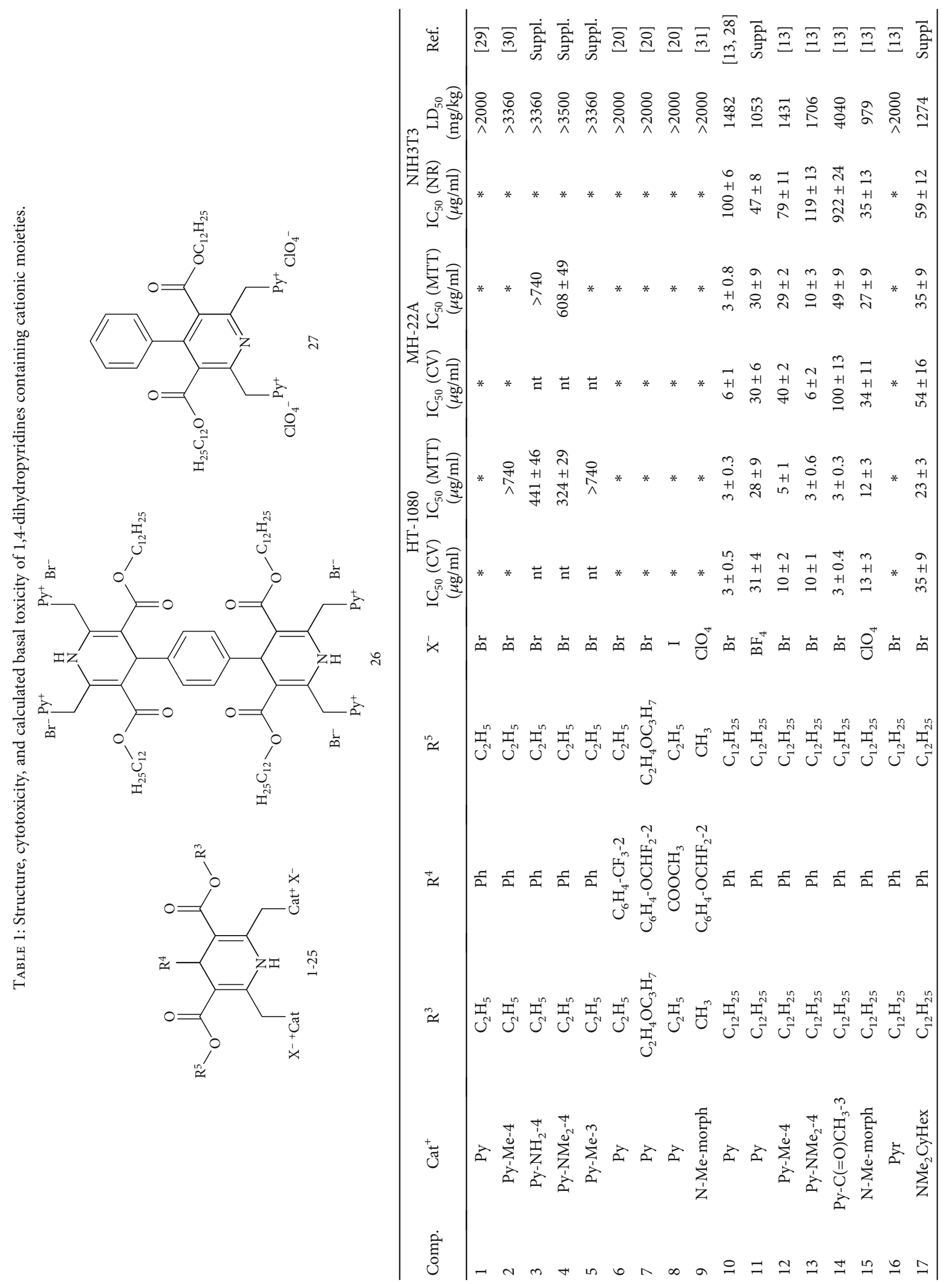


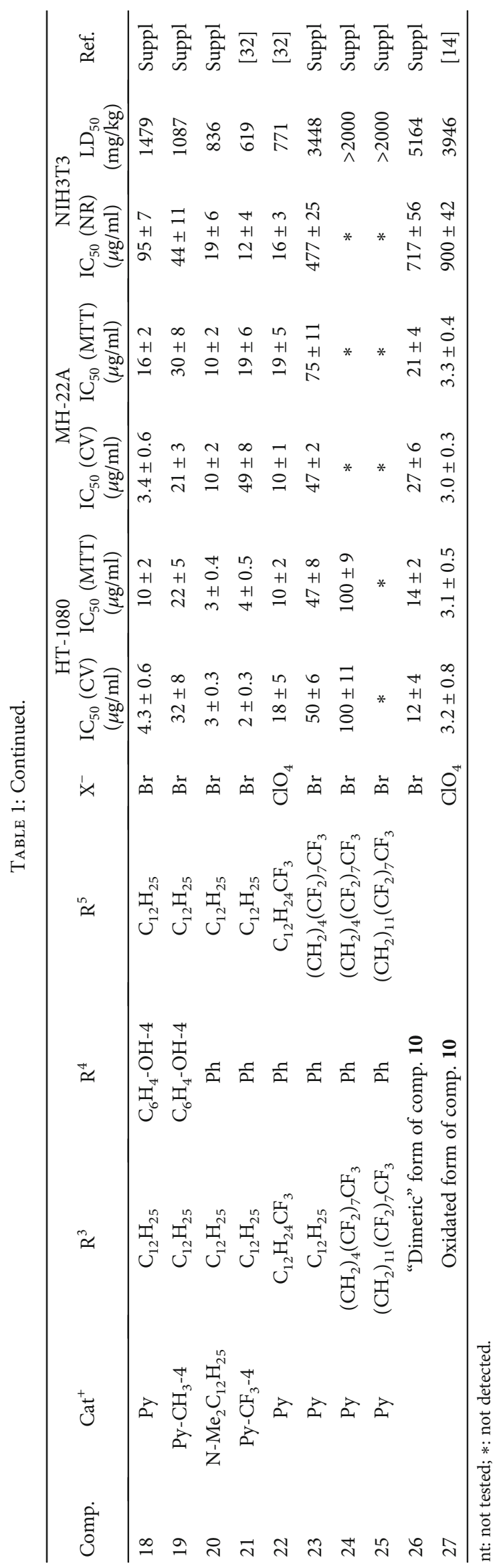




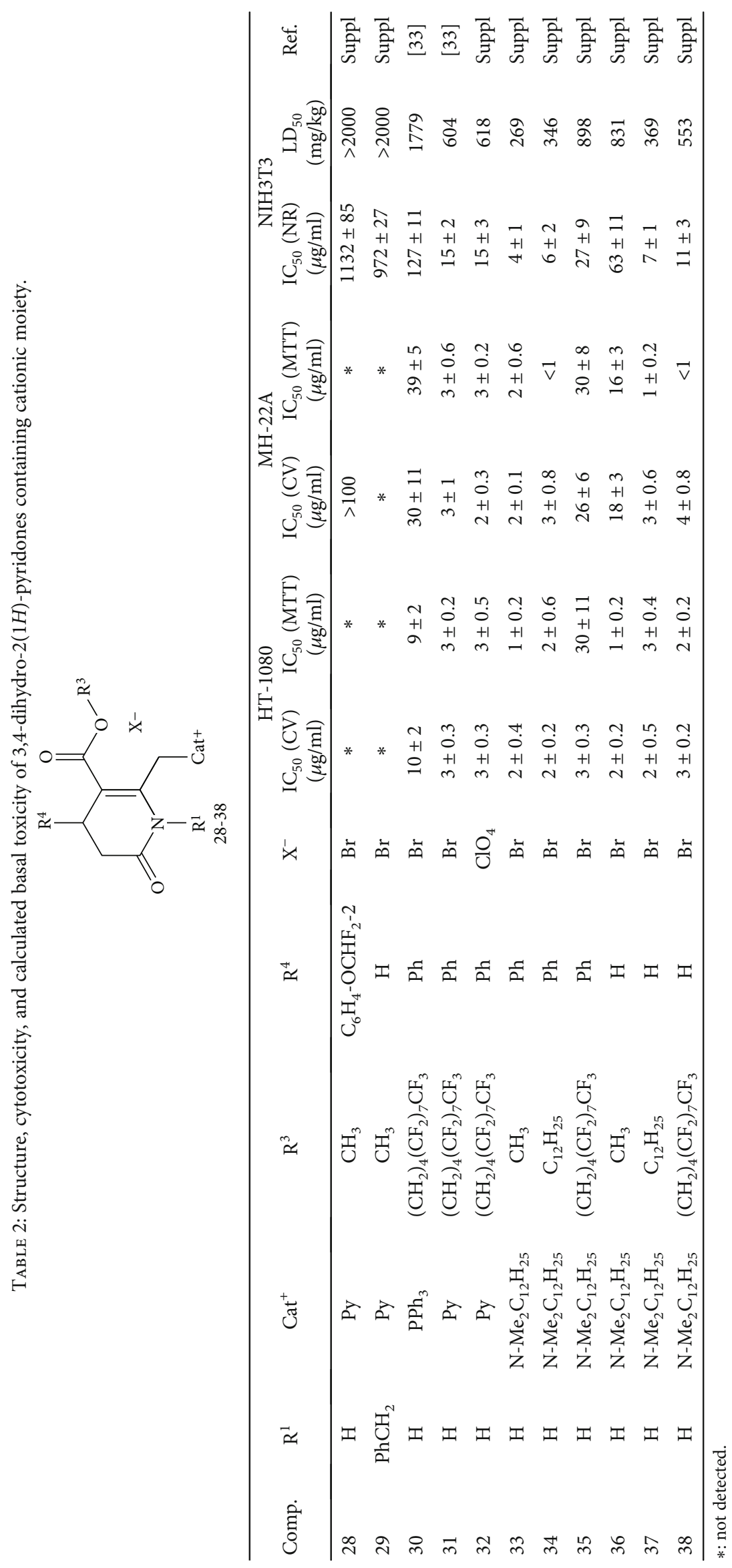


TABLE 3: Structures, cytotoxicity, and calculated toxicity of 2-amino-3-alkoxycarbonylalkylammonium halides.<smiles>[R]OC(=O)C=C([Y])N</smiles>

\begin{tabular}{|c|c|c|c|c|c|c|c|c|c|c|}
\hline \multirow[b]{2}{*}{ Comp. } & \multirow[b]{2}{*}{$\mathrm{Cat}^{+}$} & \multirow[b]{2}{*}{$\mathrm{R}$} & \multirow[b]{2}{*}{$\mathrm{X}^{-}$} & \multicolumn{2}{|c|}{ HT-1080 } & \multicolumn{2}{|c|}{ MH-22A } & \multicolumn{2}{|c|}{ NIH3T3 } & \multirow[b]{2}{*}{ Ref. } \\
\hline & & & & $\begin{array}{c}\mathrm{IC}_{50}(\mathrm{CV}) \\
(\mu \mathrm{g} / \mathrm{ml})\end{array}$ & $\begin{array}{c}\mathrm{IC}_{50}(\mathrm{MTT}) \\
(\mu \mathrm{g} / \mathrm{ml})\end{array}$ & $\begin{array}{c}\mathrm{IC}_{50}(\mathrm{CV}) \\
(\mu \mathrm{g} / \mathrm{ml})\end{array}$ & $\begin{array}{c}\mathrm{IC}_{50}(\mathrm{MTT}) \\
(\mu \mathrm{g} / \mathrm{ml})\end{array}$ & $\begin{array}{c}\mathrm{IC}_{50}(\mathrm{NR}) \\
(\mu \mathrm{g} / \mathrm{ml})\end{array}$ & $\begin{array}{c}\mathrm{LD}_{50} \\
(\mathrm{mg} / \mathrm{kg})\end{array}$ & \\
\hline 39 & $\mathrm{~N}-\mathrm{Me}_{2} \mathrm{CyHex}$ & $\mathrm{C}_{16} \mathrm{H}_{33}$ & $\mathrm{Cl}$ & $0.35 \pm 0.06$ & $0.5 \pm 0.1$ & $1 \pm 0.6$ & $0.2 \pm 0.06$ & $0.7 \pm 0.1$ & 97 & Suppl \\
\hline 40 & $\mathrm{~N}-\mathrm{Me}\left(\mathrm{CH}_{2}\right)_{4}$ & $\mathrm{C}_{16} \mathrm{H}_{33}$ & $\mathrm{Cl}$ & $<1$ & $<1$ & $1 \pm 0.2$ & $<1$ & $8 \pm 1$ & 312 & Suppl \\
\hline 41 & $\mathrm{~N}-\mathrm{Me}_{2}\left(\mathrm{CH}_{2}\right)_{2} \mathrm{NMe}_{2}$ & $\mathrm{C}_{16} \mathrm{H}_{33}$ & $\mathrm{Cl}$ & $2 \pm 0.3$ & $2 \pm 0.6$ & $1 \pm 0.3$ & $1 \pm 0.2$ & $5 \pm 1$ & 286 & Suppl \\
\hline 42 & $\begin{array}{c}\mathrm{N}- \\
\mathrm{Me}\left(\mathrm{CH}_{2}\right)_{2} \mathrm{~N}\left(\mathrm{CH}_{2}\right)_{2} \mathrm{Me}\end{array}$ & $\mathrm{C}_{16} \mathrm{H}_{33}$ & $\mathrm{Cl}$ & $2 \pm 0.4$ & $2 \pm 0.2$ & $1 \pm 0.1$ & $2 \pm 0.3$ & $4 \pm 1$ & 237 & Suppl \\
\hline 43 & $\mathrm{~N}-\mathrm{Me}_{2} \mathrm{C}_{6} \mathrm{H}_{13}$ & $\mathrm{C}_{16} \mathrm{H}_{33}$ & $\mathrm{Cl}$ & $3 \pm 0.6$ & $2 \pm 0.4$ & $2 \pm 0.2$ & $1 \pm 0.2$ & $21 \pm 6$ & 538 & Suppl \\
\hline 44 & $\mathrm{~N}-\mathrm{Me}_{2} \mathrm{C}_{12} \mathrm{H}_{25}$ & $\mathrm{C}_{16} \mathrm{H}_{33}$ & $\mathrm{Br}$ & $3 \pm 0.4$ & $3 \pm 0.3$ & $25 \pm 3$ & $28 \pm 6$ & $31 \pm 8$ & 697 & Suppl \\
\hline 45 & $\mathrm{~N}-\mathrm{Me}_{2} \mathrm{C}_{12} \mathrm{H}_{25}$ & $\mathrm{C}_{16} \mathrm{H}_{33}$ & $\mathrm{Cl}$ & nt & nt & $\mathrm{nt}$ & nt & $25 \pm 9$ & 573 & Suppl \\
\hline 46 & $\mathrm{~N}-\mathrm{Me}_{2} \mathrm{C}_{12} \mathrm{H}_{25}$ & $\mathrm{C}_{16} \mathrm{H}_{33}$ & I & $\mathrm{nt}$ & nt & nt & nt & $34 \pm 8$ & 637 & Suppl \\
\hline 47 & Py & $\mathrm{C}_{12} \mathrm{H}_{25}$ & I & $3 \pm 0.4$ & nt & $2 \pm 0.1$ & nt & $14 \pm 9$ & 403 & Suppl \\
\hline 48 & $\mathrm{~N}-\mathrm{Me}_{2} \mathrm{C}_{12} \mathrm{H}_{25}$ & $\mathrm{C}_{10} \mathrm{H}_{21}$ & $\mathrm{Cl}$ & $3 \pm 0.4$ & $\mathrm{nt}$ & $2 \pm 0.2$ & $\mathrm{nt}$ & $17 \pm 3$ & 485 & Suppl \\
\hline
\end{tabular}

nt: not tested.

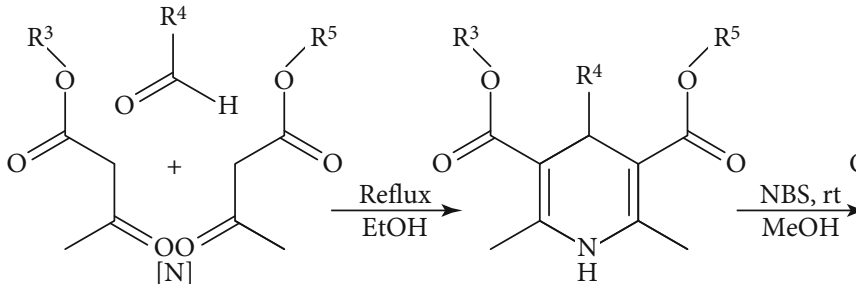

[N]: $\mathrm{NH}_{2} \mathrm{OH} ; \mathrm{H}_{3} \mathrm{COO}^{-} \mathrm{N}^{+} \mathrm{H}_{4}$ 1: $\mathrm{R}^{3}=\mathrm{R}^{5}=\mathrm{C}_{2} \mathrm{H}_{5}$ 2: $\mathrm{R}^{3}=\mathrm{R}^{5}=\mathrm{C}_{12} \mathrm{H}_{25}$<smiles>[R]OC(=O)C1=C(CBr)NC(CBr)=C(C(=O)O[R])C1C(=O)O[R]</smiles>

$1-7,9-22,26$

Scheme 1: Synthesis of 1,4-dihydropyridine (1,4-DHP) amphiphiles 1-7, 9-22, and 26.

acetic acid [40]. The parent DHPDO solution in chloroform was treated with bromine affording the respective 6-bromomethyl-DHPDO, which on subsequent reaction with pyridine or N,N-dimethyldodecyl-1-amine in dry acetone yielded the corresponding amphiphilic DHPDO derivatives 28-38.

Typically, enaminones have been studied and used as precursors and synthons for the synthesis of novel heterocyclic systems: pyridines, pyrroles, pyrimidines, dihydropyridines, etc. [41]. Therefore, up to now, most of the research in the field of enamines have been devoted to the elaboration of new strategies and synthetic methods, but lack biological studies [42]. 2-Amino-3-alkoxycarbonylalkylammonium halides with long alkyl chains have appeared as a new class of enaminoesters and were elaborated as a transfection agent for RNS transfection [27]. Also, structure analogues-alkyl acyl carnitine esters-were synthesized and characterized as biocompatible cationic lipids for use in gene delivery [43]. Cationic enaminoesters are stable solid compounds with remarkable solubility in water. The synthetic procedure for 2-amino-3-alkoxycarbonylalkylammonium halides $39-48$ is provided in Scheme 4. Briefly, the first step included the transesterification of commercially available ethyl 4chloroacetoacetate with the corresponding carbinol without solvent by azeotropic removal of ethanol. Further reaction of the corresponding 4-chloro-3-oxobutanoates with ammonium acetate led to the formation of enaminoesters, which were used for quaternization with tertiary amines or heterocycles by extended heating in a dry solvent. Potassium iodide or sodium bromide additives were used for obtaining the corresponding iodides or bromides.

The perchlorates of amphiphiles 9, 15, 22, 27, and 32 were obtained from the corresponding bromides by treating with excess of conc. $\mathrm{HClO}_{4}$ according to the procedure elaborated by Turovska et al. [44]. In some cases, the perchlorates were used for obtaining solid salts while the corresponding bromides existed as oils, and it was not possible to isolate them from the reaction mixture.

The full description of the synthesis and characterization of the original compounds in detail are given in the Supplementary data. Purity of the studied compounds was at least 
<smiles>[R5]CCCOC(=O)CC(C)=O</smiles>
$\mathrm{Rf}_{8}=\left(\mathrm{CF}_{2}\right)_{7} \mathrm{CF}_{3}$

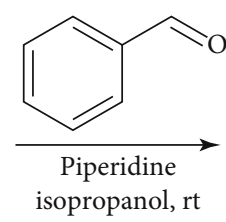
isopropanol, $r$<smiles>[R5]CC(C)OC(=O)C(=Cc1ccccc1)C(C)=O</smiles>

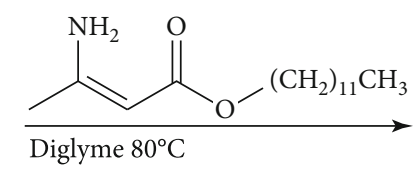

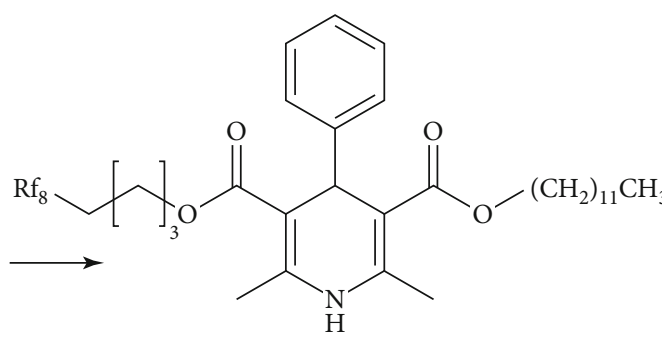

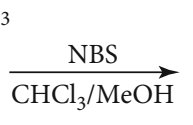<smiles>[R18]CCOC(=O)C1=C(CBr)NC(CBr)=C(C(=O)OCCCCCCCC)C1c1ccccc1</smiles>

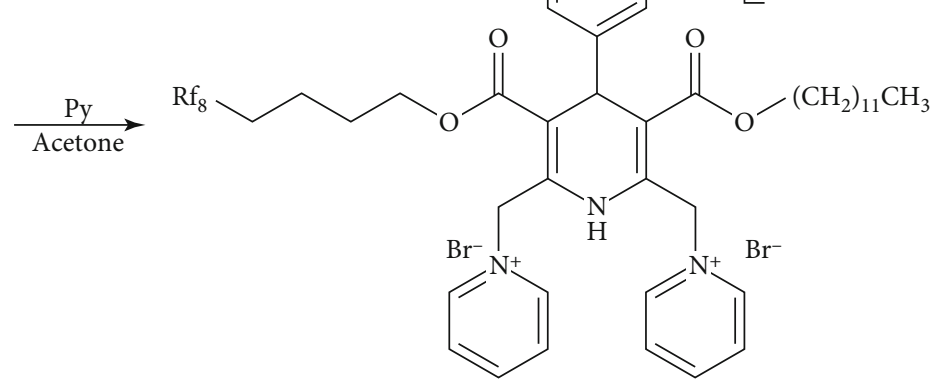

23

Scheme 2: Synthesis of unsymmetrical 1,4-DHP amphiphile 23.<smiles></smiles>
$\mathrm{NH}_{4} \mathrm{OAc}$ Scheme 3: Synthesis of 3,4-dihydro-2(1H)-pyridone (DHPDO) amphiphiles 28-38.<smiles>[R]OC(=O)CC(=O)CCl</smiles>

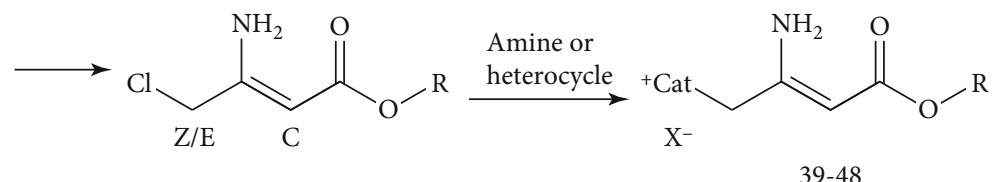

Scheme 4: Synthesis of 2-amino-3-alkoxycarbonylalkylammonium halides 39-48. 
97\% according to high-performance liquid chromatography (HPLC) data.

3.3. Estimation of $L D_{50}$ from $I C_{50}$ Values. It has been proposed that the equation from the correlation of $\mathrm{IC}_{50}$ (the concentration of a substance that causes $50 \%$ toxicity in vitro) could be applied to estimate unknown $\mathrm{LD}_{50}$ values for a new compound from $\mathrm{IC}_{50}$ values measured as basal cytotoxicity in vitro. This estimated $\mathrm{LD}_{50}$ gives prior information regarding compound properties and would be used to select promising compounds and a starting dose for in vivo experiments. The evaluation of cytotoxicity of the abovementioned 3 types of amphiphilic compounds in vitro was assessed using the 3-(4,5-dimethylthiazol-2-yl)-2,5-diphenyltetrazolinium bromide (MTT) and crystal violet (CV) assays on two monolayer tumor cell lines, namely, HT-1080 (human fibrosarcoma) and $\mathrm{MH}-22 \mathrm{~A}$ (mouse hepatoma). Additionally, the compound influence on "normal" mouse fibroblasts (NIH3T3) was estimated for the studies of structure-activity relationships and exploration of the effect of substituents. The results are presented in Tables 1-3. Studies of cytotoxicity of the amphiphilic self-assembling compounds revealed certain regularities.

\subsection{Analysis of Structure-Activity Relationships}

\subsubsection{Two Cationic Moieties Containing 1,4-DHP Amphiphiles (Table 1)}

(1) Modification of Ester Alkyl Groups. Compounds possessing short alkyl chains in the ester groups at positions 3 and 5 of the dihydropyridine ring and organic heterocyclic cations in the methylene groups in positions 2 and 6 had very low cytotoxicity in cancer cell lines HT-1080 and MH-22A and high calculated $\mathrm{LD}_{50}$ values (comp. 1-9). It means that the compounds were almost inert to the noncancerous cell line NIH3T3 and cancer cell lines HT-1080 and MH-22A. This refers to several groups of the mentioned type of compounds possessing short alkyls in 3,5-ester substituents (methyl, ethyl, and also the more elongated propoxyethyl groups): comp. 9, 1, 6, 8, and 7. Additionally, 3,5-bis(diethyloxycarbonyl)-1,4-DHP amphiphiles comprising substituted pyridinio moieties in positions 2 and 6 (compounds 2-5) have moderate cytotoxicity, around $3300 \mathrm{mg} / \mathrm{kg}$. In most cases, for the 3,5-bis(diethyloxycarbonyl)-1,4-DHP compounds, it was not possible to calculate $\mathrm{IC}_{50}$ values for the cancer cell lines HT-1080 and MH-22A due to rather low cytotoxicities; calculated $\mathrm{LD}_{50}$ values of compounds 1-9 were $>2000 \mathrm{mg} / \mathrm{kg}$ (for NIH3T3 cells).

On the contrary, analogues comprising dodecyl chains in the ester groups at positions 3 and 5 and pyridinium moieties in positions 2 and 6 of the dihydropyridine ring (see comp. 10 versus comp. 1, comp. 12 versus comp. 2, comp. 13 versus comp. 4) showed significant cytotoxicity towards cancer cell lines HT-1080 and MH-22A and still very low cytotoxicity in noncancerous NIH3T3 cells. For example, $\mathrm{LD}_{50}$ values for compounds 10,12 , and 13 were 1482,1431 , and $1706 \mathrm{mg} / \mathrm{kg}$, respectively, while cytotoxicity towards HT-1080 cells was $3-10 \mu \mathrm{g} / \mathrm{ml}$ and towards
MH-22A cells was $3-40 \mu \mathrm{g} / \mathrm{ml}$. In principle, the obtained data coincide with observations on the impact of dihydropyridine on cell growth, where it was concluded that a long alkyl chain containing 1,4-DHP amphiphiles show promising dual activity-proliferation inhibition on cancer cell lines and proliferation stimulating effect on normal cell lines [31]. It should be noted that the 3,5-bis(dodecyloxycarbonyl)-1,4-DHP amphiphile $\mathbf{1 4}$ with an electronwithdrawing acetyl group in the pyridinium moieties in positions 2 and 6 of the 1,4-DHP ring was practically nontoxic on noncancerous NIH3T3 cells and demonstrated selective cytotoxicity toward cancer cells and pronounced cytotoxicity of around $3 \mu \mathrm{g} / \mathrm{ml}$ on HT-1080 cells and of $50-100 \mu \mathrm{g} / \mathrm{ml}$ on $\mathrm{MH}-22 \mathrm{~A}$ cells.

Substitution of fluorine for hydrogen atoms in alkyl chains of the 1,4-DHP amphiphiles decreased cytotoxicity of the abovementioned compounds. Thus, substitution of the 3,5-dodecyloxycarbonyl alkyl chain's most distant hydrogen atom by trifluoromethyl groups (comp. 22 versus comp. 10) leads to lower cytotoxicity to cancer cell lines HT-1080 $(10-18 \mu \mathrm{g} / \mathrm{ml}$ versus $3 \mu \mathrm{g} / \mathrm{ml})$ and $\mathrm{MH}-22 \mathrm{~A}(10-19 \mu \mathrm{g} / \mathrm{ml}$ versus $3-6 \mu \mathrm{g} / \mathrm{ml}$ ) and to higher cytotoxicity to noncancerous cell line NIH3T3 (771 mg/kg versus $1482 \mathrm{mg} / \mathrm{kg}$ ). In this case, the influence of the anion was not taken into account, but that also could give an effect. Substitution of seven methylene groups of a 3-dodecyloxy moiety by seven difluoromethylene groups leads to the formation of an unsymmetrical 1,4-DHP amphiphile 23, which has lower cytotoxicity to the studied cancer and normal cell lines (comp. 23 versus comp. 10) - a cytotoxicity of around $47-75 \mu \mathrm{g} / \mathrm{ml}$ versus $3-6 \mu \mathrm{g} / \mathrm{ml}$ on cancer cell lines and $\mathrm{LD}_{50} 3448 \mathrm{mg} / \mathrm{kg}$ versus $1482 \mathrm{mg} / \mathrm{kg}$, respectively. Further substitution of the next seven methylene groups by seven difluoromethylene groups (comp. 24) leads to subsequent diminishing of cytotoxicity to cancer cell lines (around $100 \mu \mathrm{g} / \mathrm{ml}$ ) and also low calculated toxicity to noncancerous cell line NIH3T3 $(>2000 \mathrm{mg} / \mathrm{kg})$. In the case of the more extended partially fluorinated 3,5-heptadecafluorononadecyl chains (comp. 25), the compounds revealed undetectable toxicity to the two cancer cell lines and also low toxicity to the noncancerous cell line NIH3T3. So, from the obtained results (Table 1), it is evident that the perfluorinated 1,4-DHP amphiphiles (compounds 23-25) are nontoxic in the tested cell lines.

(2) Modification of Substituents at Position 4 of the 1,4-DHP Ring. Variations of several types of substituents in position 4 of the DHP ring of 3,5-bis(diethyloxycarbonyl)-1,4-DHPs were performed. Compounds with phenyl (comp. 1-5), substituted phenyl (2-difluoromethylphenyl (comp. 7 and 9), trifluoromethyl (comp. 6)), and ethoxycarbonyl (comp. 8) substituents were obtained, but no significant influence on the cytotoxicity of the tested 1,4-DHP amphiphiles was observed. Introducing an HO-substituent in a phenyl moiety in position 4 of the 1,4-DHP ring gives comp. 18 and 19 which are 4-(4'-hydroxyphenyl) analogues of corresponding 4-phenyl-DHPs $\mathbf{1 0}$ and $\mathbf{1 2}$, respectively. It was demonstrated that the introduction of an HO-substituent does not give a strong influence on the cytotoxicity of the compounds. 
(3) Modification of the Cationic Moieties. Modification of the cationic moieties in positions 2 and 6 of the 1,4DHP ring (in the case of 3,5-dodecyloxycarbonyl substituents) may result in substantially different toxicological properties. The insertion of substituents in the pyridinium ring leads to some quantitative modifications of cytotoxicity-mainly to slightly diminished cytotoxicity in the case of 4-methyl and 4-dimethylamino substituents (comp. 12 and comp. 13)-while introducing a 3-acyl substituent (comp. 14 versus comp. 10) in the pyridinium moiety did not give any influence on the cytotoxicity in HT1080 cells (in both cases around $3 \mu \mathrm{g} / \mathrm{ml}$ ), but decreased cytotoxicity in MH-22A cells $(50-100 \mu \mathrm{g} / \mathrm{ml}$ and 3$6 \mu \mathrm{g} / \mathrm{ml}$, respectively) and also decreased cytotoxicity in noncancerous cell line NIH3T3 (4040 mg/kg versus $1482 \mathrm{mg} / \mathrm{kg}$ ). Comparison of the cytotoxicity of the compounds with 4-methylpyridinium and 4-trifluoromethyl pyridinium moieties (comp. 12 versus comp. 21) showed that there are no significant changes of cytotoxicity in cancer HT-1080 and $\mathrm{MH}-22 \mathrm{~A}$ cells $(5-10 \mu \mathrm{g} / \mathrm{ml}$ versus 2$4 \mu \mathrm{g} / \mathrm{ml}$, and $29-40 \mu \mathrm{g} / \mathrm{ml}$ versus $19-49 \mu \mathrm{g} / \mathrm{ml}$, respectively) but a twofold increase of cytotoxicity in noncancerous NIH3T3 cells ( $1431 \mathrm{mg} / \mathrm{kg}$ versus $619 \mathrm{mg} / \mathrm{kg})$. Introduction of a pyrazinium moiety instead of a pyridinium moiety (comp. 16 versus comp. 10) gave a compound which was practically inert to the studied cancer cell lines HT-1080 and $\mathrm{MH}-22 \mathrm{~A}$ and was also nontoxic to normal NIH3T3 cells. Exchange of the heteroaromatic pyridinium moieties to saturated heterocyclic moieties-N-methylmorpholinium fragments (comp. 15) -led to slightly lower anticancer activity of the compound towards the abovementioned cancer cell lines and comparatively higher cytotoxicity to NIH3T3 cells $(979 \mathrm{mg} / \mathrm{kg})$. Also, in this case, the influence of the anion was not taken into account, but it may give an effect $\left(\mathrm{ClO}_{4}\right.$ instead of $\mathrm{Br}^{-}$). Introducing $\mathrm{N}, \mathrm{N}$-dimethylcyclohexylammonium moieties as the cationic part of the amphiphile gave compound 17 with less cytotoxicity $(23-54 \mu \mathrm{g} / \mathrm{ml})$ on both tested cancer cell lines and an $\mathrm{LD}_{50}$ value of $1274 \mathrm{mg} / \mathrm{kg}$, while the $\mathrm{LD}_{50}$ value of compound $\mathbf{1 8}$ with the introduced aliphatic N,N-dimethyl-N-dodecylammonium moieties was $836 \mathrm{mg} / \mathrm{kg}$. It was shown that compound 18 with aliphatic ammonium fragments was more cytotoxic. The obtained data is in agreement with conclusions by $\mathrm{Lv}$ et al. that among the synthetic cationic delivery systems, quaternary ammonium surfactants are more toxic than their analogues with the cationic charge delocalized in a heterocyclic system [45].

(4) Change of the Anions. Insertions of the $\mathrm{BF}_{4}{ }^{-}$anion instead of the usual $\mathrm{Br}^{-}$anion (comp. 11 versus comp. 10) lead to an increase in basal toxicity-1053 and $1482 \mathrm{mg} / \mathrm{kg}$, respectively-but a decrease in cytotoxicity on HT-1080 (around $30 \mu \mathrm{g} / \mathrm{ml}$ and $3 \mu \mathrm{g} / \mathrm{ml}$, respectively) and $\mathrm{MH}-22 \mathrm{~A}(30 \mu \mathrm{g} / \mathrm{ml}$ and $3-6 \mu \mathrm{g} / \mathrm{ml}$, respectively) cell lines.

(5) Change of Dehydrogenation Degree. Lipid-like pyridine derivative 27 , as the oxidized form of compound 10, demonstrated very close cytotoxicity data to the corresponding dihydro compound $\mathbf{1 0}$, in all cases around $3 \mu \mathrm{g} / \mathrm{ml}$, while basal toxicity on noncancerous cell line NIH3T3 is significantly diminished: comp. 27 is not harmful at all $\left(\mathrm{LD}_{50}\right.$ is $3948 \mathrm{mg} / \mathrm{kg}$ ). In this case also, the influence of the anion was not taken into account, but it may give an effect $\left(\mathrm{ClO}_{4}{ }^{-}\right.$ instead of $\mathrm{Br}^{-}$).

(6) The Duplication of Moieties. Synthetic lipid-like compound 26 was obtained as a "dimeric" form of compound 10, which was proposed as a promising DNA delivery agent. Cytotoxicity data of amphiphiles (comp. 26 versus comp. 10) demonstrated that this structural modification slightly decreased cytotoxicity of the target compound 26 in both tested cancer HT-1080 and MH-22A cells (12-27 $\mu \mathrm{g} / \mathrm{ml}$ versus $3-6 \mu \mathrm{g} / \mathrm{ml}$, respectively) and also considerably decreased the $\mathrm{LD}_{50}$ value $-5164 \mathrm{mg} / \mathrm{kg}$ versus $1482 \mathrm{mg} / \mathrm{kg}$.

\subsubsection{Cationic Moiety Containing 3,4-Dihydro-2(1H)- pyridones (Table 2)}

(1) Modification of Ester Alkyl Group. Same as in the case of 1,4-DHP amphiphiles also, pyridones with a short alkyl chain - the methyl group in the ester moiety and pyridinium in the cationic part of the molecule (comp. 28 and 29) - were inert to tested cancer cells HT-1080 and MH-22A and demonstrated high calculated $\mathrm{LD}_{50}$ values $>2000 \mathrm{mg} / \mathrm{kg}$. In the case of comp. 29, the influence of the N-substituent in the pyridone and, in the case of comp. 28, the influence of substituent in the phenyl moiety at position 4 of the pyridone cycle were not taken into account. Two other methyl esters-comp. 33 and 36-demonstrated significant cytotoxicity on all the tested cell lines. This could be explained by the influence of the cationic moiety in the compound.

Substitution of fluorine for hydrogen atoms in the alkyl chain of the pyridone amphiphiles did not give a strong influence on the cytotoxicity of the compounds, and it seems that this also was dependent on the cationic moiety and other substituents of the compound. So, in the case of 4unsubstituted pyridones with the N,N-dimethylcyclohexylammonium moiety, comp. 37 with hydrogen atoms in the ester moiety and comp. $\mathbf{3 8}$ with fluorine atoms in the ester moiety demonstrated similar cytotoxicity in all of the tested cell lines, while for cytotoxicity of 4-phenyl pyridones with $\mathrm{N}, \mathrm{N}$-dimethylcyclohexylammonium moiety, comp. 34 with hydrogen atoms in the ester moiety versus comp. 35 with fluorine atoms in the NIH3T3 cells was two times higher (346 mg/kg versus $898 \mathrm{mg} / \mathrm{kg}$, respectively).

(2) Modification of Substituents at Position 4 of 3,4-Dihydro-2(1H)-pyridone Ring. The series of 3,4-dihydro-2(1H)pyridones with a phenyl substituent at position 4 of the pyridone ring and also the 4-unsubstituted ones were compared. In the case of 4-phenyl pyridone 34 and 4unsubstituted pyridone 37 , both compounds containing the same N,N-dimethylcyclohexylammonium moiety and hydrogen atoms in the alkyl chain had no significant change of cytotoxicity on the tested cell lines. While in the case of 4-phenyl pyridone 35 and 4-unsubstituted pyridone 38, both compounds containing the same N,N- 
dimethylcyclohexylammonium moiety and fluorine atoms in the alkyl chain, the 4-unsubstituted 38 possessed a slightly higher cytotoxicity- $\mathrm{LD}_{50}$ values were $553 \mathrm{mg} / \mathrm{kg}$ for comp. 38 and $898 \mathrm{mg} / \mathrm{kg}$ for comp. 35 .

(3) Change of the Anion. Change to perchlorate from the usual bromine anion (comp. 32 versus comp. 31) did not give any influence on cytotoxicity on the tested cell lines.

(4) Modification of the Cationic Moiety. It is demonstrated that the dihydropyridone amphiphile $\mathbf{3 0}$ with a triphenylphosphonium polar head group was about 3 times less cytotoxic than the analogous dihydropyridone 31 with a pyridinium head group in the NIH3T3 cells, i.e., $1779 \mathrm{mg} / \mathrm{kg}$ versus $604 \mathrm{mg} / \mathrm{kg}$. Change of pyridinium to N,N-dimethylcyclohexylammonium moiety as the cationic head group of dihydropyridone-comp. 31 versus comp. 35-led to a slightly diminished cytotoxicity on cells in the case of comp. 35. In this case, we observed the opposite relationship as for 1,4-DHP amphiphiles where it was demonstrated that quaternary ammonium surfactants are more toxic than their heterocyclic analogues. Toxicity of cationic lipids may be connected with the structure of their head groups [41].

The obtained data demonstrated that the 3,4-dihydro$2(1 H)$-pyridone amphiphiles (Table 2 ) with a pyridinium polar head group and introduced fluorine atoms in the ester moiety (comp. 31 and comp. 32) were substantially more cytotoxic to tested cells than the structurally related 1,4 DHP amphiphiles 23 and 24.

Most dihydropyridone series cationic amphiphiles show marked cytotoxicity towards cancer cells and medium cytotoxicity towards normal NIH3T3 cells: compounds possessing 1 or 2 long alkyl chains in ester and/or ammonium groups (with or without fluorine atoms on alkyl chains (comp. 31-34 and 36-38)). There is an exclusion: comp. 30 possessing the triphenylphosphonium cationic group.

The obtained data allows one to choose compounds for putative use depending on their structure. Thus, due to the polyfluorinated alkyl ester groups in the DHP molecule, low toxicity (practically inert) amphiphilic compounds can be obtained (comp. 25). Inert amphiphilic self-assembling compounds could be used as materials to form gene transfection or drug delivery nanoparticles for transmembrane transport according to the paradigm: pharmacologically inert transport vehicles should be used.

3.4.3. 2-Amino-3-alkoxycarbonylalkylammonium Halides (Table 3). The last group of delivery systems was formed by a 2-amino-3-alkoxycarbonylalkylammonium cationic moiety containing derivatives 39-48.

(1) Modification of the Cationic Moiety. The cationic moiety was changed for 2-amino-3-hexadecyloxycarbonylammonium derivatives, namely, comp. 39-43, and 45. The obtained data demonstrated that N-(2-amino-4-(hexadecyloxy)-4-oxobut-2-en-1-yl)-N,N-dimethylcyclohexanaminium chloride (comp. 39) shows the highest cytotoxicity in all the tested cell lines with a $\mathrm{LD}_{50}$ value of $97 \mathrm{mg} / \mathrm{kg}$, while alkyl moi- ety containing compounds-N-(2-amino-4-(hexadecyloxy)4-oxobut-2-en-1-yl)-N,N-dimethylhexan-1-aminium chloride (comp. 43) and $\mathrm{N}$-(2-amino-4-(hexadecyloxy)-4-oxobut-2-en-1-yl)-N,N-dimethyldodecan-1-aminium chloride (comp. 45)-demonstrated lower cytotoxicity in all the tested cell lines with $\mathrm{LD}_{50}$ values of 538 and $573 \mathrm{mg} / \mathrm{kg}$, respectively.

(2) Modification of the Ester Alkyl Groups. The influence of the alkyl moiety was compared for two amphiphiles-comp. 48 with decyl ester versus comp. 45 with hexadecyl ester. The obtained $\mathrm{LD}_{50}$ data show that the difference is not large- $485 \mathrm{mg} / \mathrm{kg}$ versus $573 \mathrm{mg} / \mathrm{kg}$, respectively.

(3) Change of the Anion. The anions from the usual bromide comp. 44 were changed to chloride and also to iodide (comp. 45 and comp. 46). According to $\mathrm{IC}_{50}$ and $\mathrm{LD}_{50}$ data, the change of the anion did not have any influence on the cytotoxicity in NIH3T3 cell lines; $\mathrm{IC}_{50}$ values were around $30 \mu \mathrm{g} / \mathrm{ml}$.

3.5. Electrochemical Oxidation. The electrochemical oxidation of various 1,4-dihydropyridine derivatives has been extensively studied [46-50] including 1,4-DHP derivatives containing cationic moieties [29, 44]. The electrochemical oxidation of the selected compounds studied in this work was performed by cyclic voltammetry on a stationary glassy carbon electrode in dry acetonitrile; the data is presented in Table 4. The perchlorates of the tested amphiphiles were obtained from the corresponding bromides by treating their abs. $\mathrm{MeOH}$ solutions with excess of conc. $\mathrm{HClO}_{4}$ according to the procedure elaborated by Turovska et al. [44].

Now, we have used electrooxidation potentials to characterize electron donor properties of the studied compounds.

Compounds from the 1st group, containing cationic pyridinium methylene groups in positions 2 and 6 in the 1,4DHP ring, have electrooxidation potentials of $1.57-1.58 \mathrm{~V}$ both in the case of 3,5-diethoxycarbonyl- and 3,5-didodecyloxycarbonyl-1,4-DHPs (comp. 1 and comp. 10). This is also in agreement with our previous results, where the electrochemical oxidation potential of comp. 1 was determined as $1.7 \mathrm{~V}$ and electrochemical oxidation of this compound was demonstrated as a two-electron process [29]. Introduction of the $\mathrm{CF}_{3}$ groups at the $\triangle$-carbon atom of a dodecyl chain in the ester moieties (comp. 18) does not change the value of the electrooxidation potential, which is also $1.57 \mathrm{~V}$. On the contrary, the addition of a $\mathrm{CF}_{3}$ group in the pyridinium moiety in the 2 and 6 positions of the 1,4-DHP cycle (comp. 21) leads to a slight increase of the electrooxidation potential $(1.63 \mathrm{~V})$. Moreover, a change of the 17 terminal $\mathrm{H}$ atoms to $\mathrm{F}$ atoms in one or both dodecyl chains leads to a further increase of the electrooxidation potential of 1.69$1.70 \mathrm{~V}$ (comp. 23 and comp. 24). It should be noted that the parent compounds-1,4-DHP derivatives without cationic moieties-demonstrated lower electrooxidation potentials. Thus, 4-phenyl-substituted Hantzsch 1,4-dihydropyridine has a $1.08 \mathrm{~V}$ potential on a glassy carbon electrode [50] and the other 4-aryl-substituted 1,4-DHPs have $1.11 \mathrm{~V}$ potentials [51], but 4-monoalkyl-substituted 1,4- 


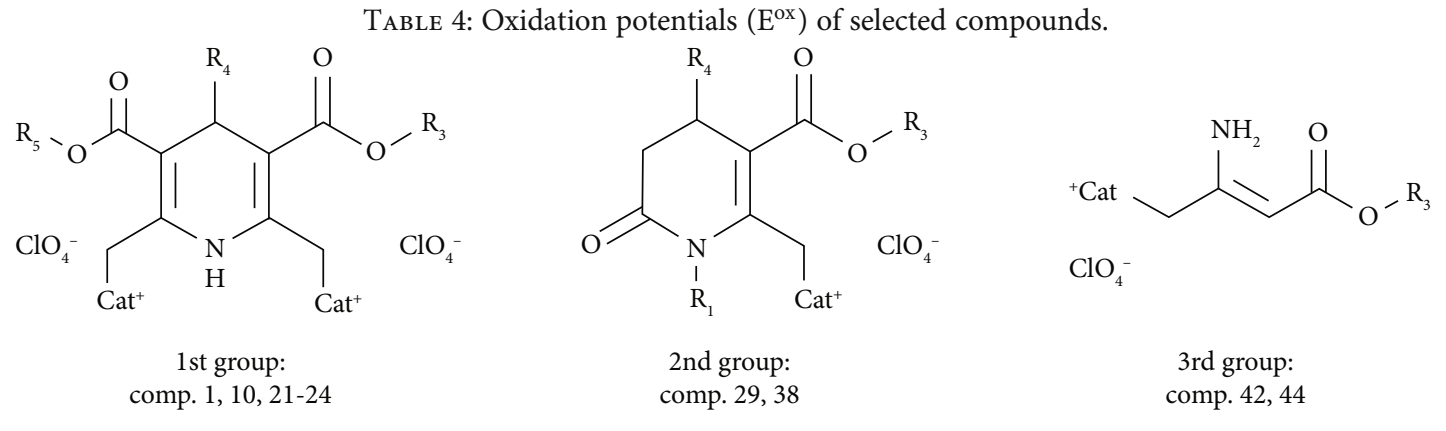

\begin{tabular}{cccccccc}
\hline Group & Comp. & $\mathrm{R}^{1}$ & $\mathrm{R}^{3}$ & $\mathrm{R}^{4}$ & $\mathrm{R}^{5}$ & $\mathrm{Cat}^{+}$ & $\mathrm{E}^{\text {ox }}(\mathrm{V})$ \\
\hline 1st & $\mathbf{1}^{*}$ & - & $\mathrm{C}_{2} \mathrm{H}_{5}$ & $\mathrm{Ph}$ & $\mathrm{C}_{2} \mathrm{H}_{5}$ & $\mathrm{Py}$ & 1.57 \\
& $\mathbf{1 0}^{*}$ & - & $\mathrm{C}_{12} \mathrm{H}_{25}$ & $\mathrm{Ph}$ & $\mathrm{C}_{12} \mathrm{H}_{25}$ & $\mathrm{Py}$ & 1.58 \\
& $\mathbf{2 1}^{*}$ & - & $\mathrm{C}_{12} \mathrm{H}_{25}$ & $\mathrm{Ph}$ & $\mathrm{C}_{12} \mathrm{H}_{25}$ & $\mathrm{Py}-\mathrm{CF}_{3}-4$ & 1.63 \\
& $\mathbf{2 2}$ & - & $\mathrm{C}_{12} \mathrm{H}_{24} \mathrm{CF}_{3}$ & $\mathrm{Ph}$ & $\mathrm{C}_{12} \mathrm{H}_{24} \mathrm{CF}_{3}$ & $\mathrm{Py}$ & 1.57 \\
& $\mathbf{2 3}^{*}$ & - & $\mathrm{C}_{12} \mathrm{H}_{25}$ & $\mathrm{Ph}$ & $\left(\mathrm{CH}_{2}\right)_{4}\left(\mathrm{CF}_{2}\right)_{7} \mathrm{CF}_{3}$ & $\mathrm{Py}$ & 1.70 \\
& $\mathbf{2 4}^{*}$ & - & $\left(\mathrm{CH}_{2}\right)_{4}\left(\mathrm{CF}_{2}\right)_{7} \mathrm{CF}_{3}$ & $\mathrm{Ph}$ & $\left(\mathrm{CH}_{2}\right)_{4}\left(\mathrm{CF}_{2}\right)_{7} \mathrm{CF}_{3}$ & $\mathrm{Py}$ & 1.69 \\
\multirow{3}{*}{ 2nd } & $\mathbf{2 9}^{*}$ & $\mathrm{PhCH}_{2}$ & $\mathrm{CH}_{3}$ & $\mathrm{H}$ & - & $\mathrm{Py}$ & 2.35 \\
& $\mathbf{3 8}^{*}$ & $\mathrm{H}$ & $\left(\mathrm{CH}_{2}\right)_{4}\left(\mathrm{CF}_{2}\right)_{7} \mathrm{CF}_{3}$ & $\mathrm{Ph}$ & - & $\mathrm{Py}$ & 2.04 \\
& $\mathbf{4 2}^{*}$ & - & $\mathrm{C}_{16} \mathrm{H}_{33}$ & - & - & $\mathrm{N}-\mathrm{Me}\left(\mathrm{CH}_{2}\right)_{2} \mathrm{~N}\left(\mathrm{CH}_{2}\right)_{2} \mathrm{Me}$ & 1.49 \\
& $\mathbf{4 4}^{*}$ & - & $\mathrm{C}_{16} \mathrm{H}_{33}$ & - & - & $\mathrm{N}-\mathrm{Me}_{2} \mathrm{C}_{12} \mathrm{H}_{25}$ & 1.24 \\
\hline
\end{tabular}

* Original compounds-bromide; ${ }^{*}$ original compound-chloride.

dihydropyridines at the same conditions have $1.01-1.03 \mathrm{~V}$ oxidation potentials [47].

Compounds from the 2nd group-amphiphilic 3,4dihydropyridone derivatives with a pyridinium methylene moiety in position 6-have more positive electrooxidation potential. So, the unsubstituted at position 4 pyridone derivative 29 has an electrooxidation potential of $2.35 \mathrm{~V}$. A compound possessing a phenyl substituent at position 4 and a 5-heptadecylfluorododecylcarboxy moiety in position 5 (comp. 38) has a slightly lower oxidation potential $(2.04 \mathrm{~V})$, while the parent 4-unsubstituted or 4-phenylsubstituted 3,4-dihydropyridone derivatives without cationic moiety in position 6 have electrooxidation potentials of $1.52-1.64 \mathrm{~V}$ [52].

Compounds from the 3rd group-tested open-chain 2amino-3-alkoxycarbonylalkylammonium halides 42 and 44-have oxidation potentials of $1.49 \mathrm{~V}$ and $1.24 \mathrm{~V}$, respectively.

Compounds from the 1st group (comp. 1-24, Table 1) could be considered as analogues of 1,4-dihydronicotinamide and model compounds of redox coenzyme NAD(P)H. Many 4-aryl-1,4-DHPs possess antioxidant properties, including several $\mathrm{Ca}^{2+}$ channel blockers [53]. The antiradical activity (ARA) of two 1,4-DHPs containing cationic moieties was determined by a 1,1-diphenyl-2-picrylhydrazyl (DPPH) radical assay; the results were expressed as a percentage (\%) of the DPPH free radical scavenging, and the untreated level of the DPPH radical was designated as $100 \%[13,31]$. It was demonstrated that 3,5-didodecyloxycarbonyl-4-phenyl1,4-dihydropyridine derivatives containing pyridinium moieties showed $25-60 \%$ radical scavenging activity which are comparable with the ARA of Diludin [54] (40\%) - a widely known antioxidant. Other 1,4-DHP amphiphiles containing saturated heterocyclic moieties-N-methylmorpholinium or N-methylpyrrolidinium derivatives-demonstrated more pronounced ARA, 95\% and 54\%, respectively. For 1,4-DHP amphiphiles possessing pyridinium moieties, the positive charge is delocalized in the heteroaromatic cycle, causing ARA reduction; for example, the electron donor dimethylamino group as a substituent of pyridinium moiety leads to a lower ARA (27\%, comp. 13) [13].

3.6. Determination of $\log P$ and Molecular Topological Polar Surface Area. The lipophilicity of molecules represents their affinity for a lipophilic environment, and the lipophilicity may be expressed as $\log P[55,56]$. The molecular polar surface area (PSA) is a very useful parameter for the prediction of drug transport properties, and PSA is defined as a sum of the surfaces of polar atoms [57]. In practice, medicinal chemists use the PSA to quantify the polarity of drug molecules [58]. Data of the calculated topological polar surface area represent the compound's blood-brain barrier permeability $[59,60]$. It allows one to plan further activities for the pleiotropic compounds.

Lipid-type compounds could be used as biologically active compounds per se or as transport vehicles or additives, so their lipophilicity $(\log P)$ and topological polar surface area (TPSA) were calculated, and the data are recorded in Table 5.

$\log P$ values which surpass 5 , according to Lipinski's Rule of Five, characterize compounds as lipophilic [61]. According to the obtained data for lipid-like amphiphiles, in some cases, the values of $\log P$ were $<5$, in particular for compounds $1,2,4,6,7,28$, and 29 . These compounds comprised short alkyl moieties in the ester groups. $\log P$ values close to 5 were 
TABLE 5: $\log P$ and molecular topological polar surface area (TPSA) of selected compounds.

\begin{tabular}{|c|c|c|c|c|c|c|c|c|}
\hline Comp. & $\begin{array}{l}\text { 1st group } \\
\log P\end{array}$ & TPSA $\left(\AA^{2}\right)$ & Comp. & $\begin{array}{l}\text { 2nd group } \\
\log P\end{array}$ & TPSA $\left(\AA^{2}\right)$ & Comp. & $\begin{array}{l}\text { 3rd group } \\
\log P\end{array}$ & TPSA $\left(\AA^{2}\right)$ \\
\hline 1 & 2.26 & 70.65 & 28 & 1.44 & 67.64 & 39 & 7.52 & 52.32 \\
\hline 2 & 3.13 & 70.65 & 29 & 1.18 & 49.62 & 40 & 6.25 & 52.32 \\
\hline 4 & 2.71 & 77.13 & 30 & 14.32 & 55.40 & 41 & 5.63 & 55.56 \\
\hline 6 & 3.18 & 70.65 & 31 & 9.43 & 58.41 & 42 & 5.44 & 55.56 \\
\hline 7 & 3.20 & 98.34 & 32 & 9.43 & 58.41 & 43 & 7.98 & 52.32 \\
\hline 10 & 10.97 & 70.65 & 33 & 6.19 & 55.40 & 44 & 10.65 & 52.32 \\
\hline 12 & 11.63 & 70.65 & 34 & 10.01 & 55.40 & 47 & 5.40 & 55.33 \\
\hline 13 & 11.42 & 77.13 & 35 & 14.81 & 55.40 & 48 & 7.98 & 52.32 \\
\hline 17 & 13.55 & 64.63 & 36 & 4.70 & 55.40 & & & \\
\hline 20 & 19.81 & 64.63 & 37 & 8.52 & 55.40 & & & \\
\hline 21 & 12.81 & 70.65 & 38 & 13.32 & 55.40 & & & \\
\hline 22 & 13.22 & 70.65 & & & & & & \\
\hline 23 & 15.77 & 70.65 & & & & & & \\
\hline 24 & 18.64 & 70.65 & & & & & & \\
\hline 25 & 24.68 & 70.65 & & & & & & \\
\hline
\end{tabular}

obtained for compounds $36,41,42$, and 47, namely, 4.70, $5.63,5.44$, and 5.40, respectively. $\log P$ values for dicationic 1,4-DHP amphiphiles possessing longer alkyl chains or fluorinated alkyl groups in the ester moieties were determined in the 11-24.5 interval, while for long alkyl ester moieties containing 3,4-dihydropyridone amphiphiles, $\log P$ values were determined in the 6-15 interval. The difference could be due to the number of alkyl groups. $\log P$ values for other open-chain com12pounds were determined in the 6-11 interval.

Nevertheless, TPSA never surpasses 90, so the compounds are prone to permeate cells; additionally, they can penetrate the blood-brain barrier [62]. Among all tested amphiphiles, only for $1,1^{\prime}-((4-$-(2-(difluoromethoxy)phenyl)-3,5-bis((propoxymethoxy)carbonyl)-1,4-dihydropyridine-2,6-diyl)bis(methylene))bis(pyridin-1-ium) dibromide (comp. 7) was the TPSA value higher than 90, i.e., $98.34 \AA^{2}$. This could be explained by the influence of the structure components of the compound. TPSA values for the other compounds were defined in accordance with the main fragments of the compound structures. So, for the other 1st group compounds-dicationic 1,4-DHP amphiphiles-TPSA values were in the 71-77 $\AA^{2}$ interval; for the 2 nd group compounds-cationic 3,4-dihydropyridone amphiphiles-TPSA values were in the $50-58 \AA^{2}$ interval with the exception of compound $\mathbf{2 8}$ which had a TPSA value of $67.64 \AA^{2}$; and for the 3 rd group compounds-open-chain 2 amino-3-alkoxycarbonylalkylammonium cationic moiety containing amphiphiles-the TPSA values were in the 52$56 \AA^{2}$ interval.

\section{Conclusions}

Polyfunctional self-assembling synthetic lipid-like compounds, such as pharmacological and chemotherapeutical agents, namely, 3,5-dialkoxycarbonyl-1,4-dihydropyridines
(1,4-DHPs) comprising pyridinium or ammonium substituents at the 2 and 6 positions; structurally related compounds, derivatives of 3,4-dihydro-2-oxopyridines as isomeric 3,4dihydropyridine structures with an additional intracyclic carbonyl group; and the $\mathrm{N}$ - $\beta$-carbonylvinylamido system, namely, 2-amino-3-alkoxycarbonylalkylammonium halides as open chain analogues of the first type of the abovementioned compounds, were studied. The main properties and major functions of these compounds are their amphiphilic character, liposome-forming ability, RNA transfection (by self-assembling compounds), antiradical and antioxidant properties, growth regulation-both in malignant and nonmalignant cell types-anticancer properties due to cytotoxicity, and MDR inhibition [13, 16, 27, 28, 31, 33].

In this work we have demonstrated biological properties of cationic 1,4-dihydropyridine as self-assembling synthetic lipids and dihydropyridones as well as open-chain analogues: their cytotoxicity against cancer cell lines HT-1080 and MH$22 \mathrm{~A}$ in comparison with cytotoxicity against normal NIH3T3 cells. The obtained data showed that 1,4-DHP derivatives containing cationic moieties in positions 2 and 6 and possessing dodecyl alkyl chains in the ester groups in positions 3 and 5 demonstrated high cytotoxicity on cancer cells HT1080 and $\mathrm{MH}-22 \mathrm{~A}$, but low cytotoxicity on noncancerous NIH3T3 cells. According to our previous studies, these compounds also demonstrated significant antiradical activity and also gene delivery activity [13], and for some of them, reversal of multidrug resistance in murine lymphoma cells [16]. Together with antiradical activity, cell growth regulation, multidrug resistance inhibition, nucleic acid delivery, and the polyfunctional (pleiotropic) type of properties of the mentioned compounds open new avenues for their studies and use. According to literature data, liposomes could be used not only to transport biologically active compounds but also to have their own specific biological activity, e.g., to protect cells and encapsulated components against oxidative 
damage. Liposomes are proposed for the delivery of antioxidants for protection against pathological conditions related to oxidative stress [63]. In our case, liposomes could be used per se to protect against oxidative damage.

A calculated degree of lipophilicity and TPSA data can be used to choose compounds according to their permeability through membranes, including the blood-brain barrier, to guide them to the proper location. It was demonstrated that membrane permeability in a variety of systems, including model liposome bilayers, various cells, and epidermal tissue, correlated strongly with data regarding hydrocarbon-water partition coefficients [64]. TPSA values for selected compounds were defined in accordance with the main fragments of compound structures. The determined $\log P$ values were highest for dodecyl ester groups in positions 3 and 5 of the 1,4-DHP and lowest for short alkyl chain containing amphiphiles.

This study also revealed the correlation of the cytotoxic effects of 3 groups of structurally related synthetic cationic lipids according to their molecular structures. The results indicated that among the tested compound groups, amphiphiles based on the 1,4-DHP core demonstrated high cytotoxicity in cancer cells HT-1080 and MH-22A, but low cytotoxicity in the noncancerous NIH3T3 cells.

The obtained results may serve as guidelines for the development of drug formulations to be used in cancer treatment on the basis of these pleiotropic lipid-like 1,4-DHP amphiphiles.

\section{Data Availability}

The experimental data used to support the findings of this study are available from the corresponding authors upon request.

\section{Conflicts of Interest}

The authors declare that there is no conflict of interest regarding the publication of this paper.

\section{Acknowledgments}

This research was supported by the PostDocLatvia Project Nr.1.1.1.2/VIAA/2/18/371 "Bifunctional Amphiphilic Lipid-Like Compounds-Self-Assembling Properties and Biological Activities" (to M. Rucins) and EuroNanoMed2 Project INNOCENT "Innovative Nanopharmaceuticals: Targeting Breast Cancer Stem Cells by a Novel Combination of Epigenetic and Anticancer Drugs with Gene Therapy."

\section{Supplementary Materials}

Scheme S1: synthesis of 1,4-dihydropyridine (1,4-DHP) amphiphiles 1-7, 9-22, and 26. Scheme S2: synthesis of unsymmetrical 1,4-DHP amphiphile 23. Scheme S3: synthesis of 3,4-dihydro-2 $(1 H)$-pyridone (DHPDO) amphiphiles 28-38. Scheme S4: synthesis of 2-amino-3-alkoxycarbonylalkylammonium halides 39-48. Physicochemical characterization of new compounds is provided. (Supplementary Materials)

\section{References}

[1] T. Olusanya, R. H. Ahmad, D. Ibegbu, J. Smith, and A. Elkordy, "Liposomal drug delivery systems and anticancer drugs," Molecules, vol. 23, no. 4, p. 907, 2018.

[2] C. T. Inglut, A. J. Sorrin, T. Kuruppu et al., "Immunological and toxicological considerations for the design of liposomes," Nanomaterials, vol. 10, no. 2, p. 190, 2020.

[3] A. Carmona-Ribeiro, "Bilayer-forming synthetic lipids: drugs or carriers?," Current Medicinal Chemistry, vol. 10, no. 22, pp. 2425-2446, 2003.

[4] A. Lechanteur, V. Sanna, A. Duchemin, B. Evrard, D. Mottet, and G. Piel, "Cationic liposomes carrying siRNA: impact of lipid composition on physicochemical properties, cytotoxicity and endosomal escape," Nanomaterials, vol. 8, no. 5, p. 270, 2018.

[5] K. He and M. Tang, "Safety of novel liposomal drugs for cancer treatment: advances and prospects," Chemico-Biological Interactions, vol. 295, pp. 13-19, 2018.

[6] L. Milkovic, W. Siems, R. Siems, and N. Zarkovic, "Oxidative stress and antioxidants in carcinogenesis and integrative therapy of cancer," Current Pharmaceutical Design, vol. 20, no. 42, pp. 6529-6542, 2014.

[7] Q. Cui, J.-Q. Wang, Y. G. Assaraf et al., "Modulating ROS to overcome multidrug resistance in cancer," Drug Resistance Updates, vol. 41, pp. 1-25, 2018.

[8] H. Sies and D. P. Jones, "Reactive oxygen species (ROS) as pleiotropic physiological signalling agents," Nature Reviews. Molecular Cell Biology, vol. 21, no. 7, pp. 363-383, 2020.

[9] H. Sies, "Oxidative stress: a concept in redox biology and medicine," Redox Biology, vol. 4, pp. 180-183, 2015.

[10] A. Garu, G. Moku, S. K. Gulla et al., "Examples of tumor growth inhibition properties of liposomal formulations of pH-sensitive histidinylated cationic amphiphiles," ACS Biomaterials Science \& Engineering, vol. 1, no. 8, pp. 646-655, 2015.

[11] Z. Fasili, F. Mehri, H. A. Ebrahimi et al., "Applying nanoparticles in the treatment of viral infections and toxicological considerations," Pharmaceutical and Biomedical Research, vol. 5, no. 4, pp. 1-20, 2019, http://pbr.mazums.ac.ir/article-1-247en.html.

[12] J. Barar and Y. Omidi, "Intrinsic bio-signature of gene delivery nanocarriers may impair gene therapy goals," BioImpacts: BI, vol. 3, no. 3, pp. 105-109, 2013.

[13] K. Pajuste, Z. Hyvonen, O. Petrichenko et al., "Gene delivery agents possessing antiradical activity: self-assembling cationic amphiphilic 1,4-dihydropyridine derivatives," New Journal of Chemistry, vol. 37, no. 10, pp. 3062-3075, 2013.

[14] O. Petrichenko, M. Rucins, A. Vezane et al., "Studies of the physicochemical and structural properties of self-assembling cationic pyridine derivatives as gene delivery agents," Chemistry and Physics of Lipids, vol. 191, pp. 25-37, 2015.

[15] G. Apsite, I. Timofejeva, A. Vezane et al., "Synthesis and comparative evaluation of novel cationic amphiphile C12-Man-Q as an efficient DNA delivery agent in vitro," Molecules, vol. 23, no. 7, p. 1540, 2018.

[16] M. Cindric, A. Cipak, J. Serly et al., "Reversal of multidrug resistance in murine lymphoma cells by amphiphilic dihydropyridine antioxidant derivative," Anticancer Research, vol. 30, no. 10, pp. 4063-4069, 2010. 
[17] G. Dubur, B. Vīgante, A. Plotniece et al., "Dihydropyridine derivatives as bioprotectors," Chimica Oggi, vol. 26, no. 2, pp. 68-70, 2008.

[18] M. Rucins, P. Dimitrijevs, K. Pajuste et al., "Contribution of molecular structure to self-assembling and biological properties of bifunctional lipid-like 4-(N-alkylpyridinium)-1,4-dihydropyridines," Pharmaceutics., vol. 11, no. 3, p. 115, 2019.

[19] M. Rucins, D. Kaldre, K. Pajuste et al., "Synthesis and studies of calcium channel blocking and antioxidant activities of novel 4-pyridinium and/or N-propargyl substituted 1,4-dihydropyridine derivatives," Comptes Rendus Chimie, vol. 17, no. 1, pp. 69-80, 2014.

[20] M. Petrova, R. Muhamadejev, B. Vigante et al., "Intramolecular $\mathrm{C}-\mathrm{H} \cdots \mathrm{O}$ hydrogen bonding in 1,4-dihydropyridine derivatives," Molecules, vol. 16, no. 9, pp. 8041-8052, 2011.

[21] K. Saotome, H. Morita, and M. Umeda, "Cytotoxicity test with simplified crystal violet staining method using microtitre plates and its application to injection drugs," Toxicology in Vitro, vol. 3, no. 4, pp. 317-321, 1989.

[22] W. S. Stokes, S. Casati, J. Strickland, and M. Paris, "Neutral red uptake cytotoxicity tests for estimating starting doses for acute oral toxicity tests," Current Protocols in Toxicology, vol. 36, no. $1,2008$.

[23] Interagency Coordinating Committee on the Validation of Alternative Methods, ICCVAM test method evaluation report (TMER): in vitro cytotoxicity test methods for estimating starting doses for acute oral systemic toxicity testing, 2006, NIH Publication No: 07-4519.

[24] The national toxicology program (NTP) Interagency center for the evaluation of alternative toxicological methods (NICEATM), Background review document: in vitro cytotoxicity test methods for estimating acute oral systemic toxicity, vol. 1, 2006June 2020 https://ntp.niehs.nih.gov/iccvam/docs/ acutetox_docs/brd_tmer/brdvol1_nov2006.pdf.

[25] The national toxicology program (NTP) Interagency center for the evaluation of alternative toxicological methods (NICEATM), Background review document: in vitro cytotoxicity test methods for estimating acute oral systemic toxicity, vol. 2, 2006June 2020 https://ntp.niehs.nih.gov/iccvam/docs/ acutetox_docs/brd_tmer/brdvol2_nov2006.pdf.

[26] EP, Regulation (EC) No 1272/2008 of the European Parliament and of the Council of 16 December 2008 on classification, labelling and packaging of substances and mixtures, amending and repealing Directives 67/548/EEC and 1999/45/EC, and amending Regulation (EC), Publications office of the European Union, 2008, doi:2004R0726 - v.7 of 05.06.2013.

[27] G. Apsīte, E. Bisenieks, R. Brūvere et al., Novel biologically active enaminoester derivatives as agents for chemotherapy, LV15347B, Espacenet, 2019.

[28] Z. Hyvönen, A. Plotniece, I. Reine, B. Chekavichus, G. Duburs, and A. Urtti, "Novel cationic amphiphilic 1,4-dihydropyridine derivatives for DNA delivery," Biochimica et Biophysica Acta (BBA) - Biomembranes, vol. 1509, no. 1-2, pp. 451-466, 2000.

[29] A. Plotniece, K. Pajuste, D. Kaldre et al., "Oxidation of cationic 1,4-dihydropyridine derivatives as model compounds for putative gene delivery agents," Tetrahedron, vol. 65 , no. 40, pp. 8344-8349, 2009.

[30] K. Pajuste, I. Krivicka, M. Plotniece et al., The synthesis of new cationic 1,4-dihydropyridine derivatives for DNA delivery, Rigas Teh. Univ. Zinat. Raksti, Ser. 1 Materialzinat. Un Lietiska Kim, vol. 11, pp. 7-10, 2005, July 2020 https://ortus.rtu .lv/science/lv/publications/6433.
[31] I. Bruvere, E. Bisenieks, J. Poikans et al., "Dihydropyridine derivatives as cell growth modulators in vitro," Oxidative Medicine and Cellular Longevity, vol. 2017, 15 pages, 2017.

[32] R. Muhamadejev, M. Petrova, R. Smits et al., "Study of interactions of mononucleotides with 1,4-dihydropyridine vesicles using NMR and ITC techniques," New Journal of Chemistry, vol. 42, no. 9, pp. 6942-6948, 2018.

[33] R. Smits, Y. Goncharenko, I. Vesere et al., "Synthesis and selfassembly of novel fluorous cationic amphiphiles with a 3,4dihydro-2(1H)-pyridone spacer," Journal of Fluorine Chemistry, vol. 132, no. 6, pp. 414-419, 2011.

[34] M. Rucins, K. Pajuste, A. Sobolev et al., "Data for the synthesis and characterisation of 2,6-di(bromomethyl)-3,5-bis(alkoxycarbonyl)-4-aryl-1,4-dihydropyridines as important intermediates for synthesis of amphiphilic 1,4-dihydropyridines," Data in Brief, vol. 30, p. 105532, 2020.

[35] K. Pajuste, A. Plotniece, K. Kore et al., "Use of pyridinium ionic liquids as catalysts for the synthesis of 3,5-bis(dodecyloxycarbonyl)-1,4-dihydropyridine derivative," Central European Journal of Chemistry, vol. 9, no. 1, pp. 143-148, 2011.

[36] P. G. Nantermet, J. C. Barrow, H. G. Selnick et al., "Selective $\alpha 1$ a adrenergic receptor antagonists based on 4-aryl-3,4-dihydropyridine-2-ones," Bioorganic \& Medicinal Chemistry Letters, vol. 10, no. 15, pp. 1625-1628, 2000.

[37] K. B. Goodman, H. Cui, S. E. Dowdell et al., "Development of dihydropyridone indazole amides as selective rho-kinase inhibitors," Journal of Medicinal Chemistry, vol. 50, no. 1, pp. 6-9, 2007.

[38] X. Huang, S. Broadbent, C. Dvorak, and S. H. Zhao, "Pilotplant preparation of 3,4-dihydropyridin-2-one derivatives, the core structures of P2X7 receptor antagonists," Organic Process Research and Development, vol. 14, no. 3, pp. 612616, 2010.

[39] K. T. Homan, K. M. Larimore, J. M. Elkins, M. Szklarz, S. Knapp, and J. J. G. Tesmer, "Identification and structurefunction analysis of subfamily selective g protein-coupled receptor kinase inhibitors," ACS Chemical Biology, vol. 10, no. 1, pp. 310-319, 2014.

[40] A. Morales, E. Ochoa, M. Suárez et al., "Novel hexahydrofuro[3,4-b]-2(1H)-pyridones from 4-aryl substituted 5-alkoxycarbonyl-6-methyl-3,4-dihydropyridones," J. Heterocycl. Chem., vol. 33, no. 1, pp. 103-107, 1996.

[41] B. Vigante, A. Plotniece, M. Rucins et al., "An efficient synthesis of multisubstituted 4-nitrobuta-1,3-dien-1-amines and application in cyclisation reactions," Tetrahedron, vol. 74, no. 21, pp. 2596-2607, 2018.

[42] B. Stanovnik, "Enaminone, enaminoesters, and related compounds in the metal-free synthesis of pyridines and fused pyridines," European J. Org. Chem., vol. 2019, no. 31-32, pp. 5120-5132, 2019.

[43] J. Wang, X. Guo, Y. Xu, L. Barron, and F. C. Szoka, "Synthesis and characterization of long chain alkyl acyl carnitine esters. Potentially biodegradable cationic lipids for use in gene delivery," Journal of Medicinal Chemistry, vol. 41, no. 13, pp. 2207 2215, 1998.

[44] B. Turovska, J. Stradins, I. Turovskis, A. Plotniece, A. Shmidlers, and G. Duburs, "Electrochemical oxidation of compounds containing 1,4-dihydropyridine and pyridinium rings - analogs of gene transfection agents," Chemistry of Heterocyclic Compounds, vol. 40, no. 6, pp. 753-758, 2004. 
[45] H. Lv, S. Zhang, B. Wang, S. Cui, and J. Yan, "Toxicity of cationic lipids and cationic polymers in gene delivery," Journal of Controlled Release, vol. 114, no. 1, pp. 100-109, 2006.

[46] L. Baumane, A. Krauze, S. Belyakov et al., "Synthesis, structure, and electrochemical characteristics of 4-aryl-2-carbamoylmethylthio-5-ethoxycarbonyl-1,4-dihydropyridine-3-carboxylic acid nitriles," Chemistry of Heterocyclic Compounds, vol. 41, no. 3, pp. 362-373, 2005.

[47] B. Turovska, I. Goba, I. Turovskis et al., "Electrochemical oxidation of 4-monoalkyl-substituted 1,4-dihydropyridines," Chemistry of Heterocyclic Compounds, vol. 44, no. 12, pp. 1483-1490, 2008.

[48] L. J. Núñez-Vergara, C. López-Alarcón, P. A. NavarreteEncina, A. M. Atria, C. Camargo, and J. A. Squella, "Electrochemical and EPR characterization of 1,4-dihydropyridines. Reactivity towards alkyl radicals," Free Radical Research, vol. 37, no. 1, pp. 109-120, 2009.

[49] L. J. Núñez-Vergara, R. Salazar, C. Camargo et al., "Oxidation of C4-hydroxyphenyl 1,4-dihydropyridines in dimethylsulfoxide and its reactivity towards alkylperoxyl radicals in aqueous medium," Bioorganic \& Medicinal Chemistry, vol. 15, no. 12, pp. 4318-4326, 2007.

[50] V. Pardo-Jiménez, C. Barrientos, K. Pérez-Cruz et al., "Synthesis and electrochemical oxidation of hybrid compounds: dihydropyridine-fused coumarins," Electrochimica Acta, vol. 125, pp. 457-464, 2014.

[51] Y. P. Stradyn, Y. I. Beilis, Y. R. Uldrikis, G. Y. Dubur, A. E. Sausin, and B. S. Chekavichus, "Voltamperometry of 1,4-dihydropyridine derivatives," Chemistry of Heterocyclic Compounds, vol. 11, no. 11, pp. 1299-1303, 1975.

[52] R. Smits, B. Turovska, S. Belyakov, A. Plotniece, and G. Duburs, "Synthesis of 5-carboxy-6-methyl-3,4-dihydro-2(1H)-pyridone derivatives and their electrochemical oxidation to 2-pyridones," Chemical Physics Letters, vol. 649, pp. 84-87, 2016.

[53] A. Augustyniak, G. Bartosz, A. Čipak et al., "Natural and synthetic antioxidants: an updated overview," Free Radical Research, vol. 44, no. 10, pp. 1216-1262, 2010.

[54] G. Tirzitis, D. Tirzite, and Z. Hyvonen, "Antioxidant activity of 2,6-dimethyl-3,5-dialkoxycarbonyl-1,4-dihydropyridines in metal-ion catalyzed lipid peroxidation," Czech Journal of Food Sciences, vol. 19, no. 3, pp. 81-84, 2013.

[55] S. A. Wildman and G. M. Crippen, "Prediction of physicochemical parameters by atomic contributions," Journal of Chemical Information and Computer Sciences, vol. 39, no. 5, pp. 868-873, 1999.

[56] G. H. Goetz and M. Shalaeva, "Leveraging chromatography based physicochemical properties for efficient drug design," ADMET DMPK., vol. 6, no. 2, pp. 85-104, 2018.

[57] P. Ertl, B. Rohde, and P. Selzer, "Fast calculation of molecular polar surface area as a sum of fragment-based contributions and its application to the prediction of drug transport properties," Journal of Medicinal Chemistry, vol. 43, no. 20, pp. 37143717, 2000.

[58] G. Caron and G. Ermondi, "Molecular descriptors for polarity: the need for going beyond polar surface area," Future Medicinal Chemistry, vol. 8, no. 17, pp. 2013-2016, 2016.

[59] Z. Wang, H. Yang, Z. Wu et al., "In silico prediction of bloodbrain barrier permeability of compounds by machine learning and resampling methods," ChemMedChem, vol. 13, no. 20, pp. 2189-2201, 2018.
[60] S. Benfeito, C. Oliveira, C. Fernandes et al., "Fine-tuning the neuroprotective and blood-brain barrier permeability profile of multi-target agents designed to prevent progressive mitochondrial dysfunction," European Journal of Medicinal Chemistry, vol. 167, pp. 525-545, 2019.

[61] C. A. Lipinski, "Drug-like properties and the causes of poor solubility and poor permeability," Journal of Pharmacological and Toxicological Methods, vol. 44, no. 1, pp. 235-249, 2000.

[62] S. A. Hitchcock and L. D. Pennington, "Structure-brain exposure relationships," Journal of Medicinal Chemistry, vol. 49, no. 26, pp. 7559-7583, 2006.

[63] Z. E. Suntres, "Liposomal antioxidants for protection against oxidant-induced damage," Journal of Toxicology, vol. 2011, Article ID 152474, 16 pages, 2011.

[64] M. R. Naylor, A. M. Ly, M. J. Handford et al., "Lipophilic permeability efficiency reconciles the opposing roles of lipophilicity in membrane permeability and aqueous solubility," Journal of Medicinal Chemistry, vol. 61, no. 24, pp. 11169-11182, 2018. 